Article

\title{
Linear, Non-Conjugated Cyclic and Conjugated Cyclic Paraphenylene under Pressure
}

\author{
Miriam Peña-Álvarez $1, * \mathbb{0}$, Samuele Fanetti ${ }^{2}$, Naomi Falsini ${ }^{2}$, Giulia Novelli ${ }^{3}$, Juan Casado ${ }^{4}$, \\ Valentín G. Baonza ${ }^{5,6}$, Mercedes Taravillo ${ }^{5}$ (D), Simon Parsons ${ }^{3}$, Roberto Bini ${ }^{2}$ (D) \\ and Margherita Citroni ${ }^{2}$ \\ 1 School of Physics and Astronomy and Centre for Science at Extreme Conditions, University of Edinburgh, \\ Edinburgh EH9 3FD, UK \\ 2 LENS-European Laboratory for Non-Linear Spectroscopy, 50019 Sesto, Florence, Italy; \\ fanetti@lens.unifi.it (S.F.); nao89@hotmail.it (N.F.); roberto.bini@unifi.it (R.B.); \\ margherita.citroni@nature.com (M.C.) \\ 3 Centre for Science at Extreme Conditions and EastChem School of Chemistry, University of Edinburgh, \\ Edinburgh EH9 3FJ, UK; G.Novelli@ed.ac.uk (G.N.); Simon.Parsons@ed.ac.uk (S.P.) \\ 4 Department of Physical Chemistry, Faculty of Science, University of Málaga, CEI Andalucía Tech, Campus \\ de Teatinos s/n, 29071 Málaga, Spain; casado@uma.es \\ 5 MALTA-Consolider Team, Department of Physical Chemistry I, Chemistry Faculty, University Complutense \\ of Madrid, 28040 Madrid, Spain; vgbaonza@quim.ucm.es (V.G.B.); mtaravil@quim.ucm.es (M.T.) \\ 6 Instituto de Geociencias IGEO (CSIC-UCM), 28040 Madrid, Spain \\ * Correspondence: mpenaal@ed.ac.uk; Tel.: +44-131-651-7214
}

Academic Editors: Ines Collings, Andrew B. Cairns and Miklos Kertesz

Received: 16 August 2019; Accepted: 17 September 2019; Published: 26 September 2019

\begin{abstract}
The $n$-paraphenylene family comprises chains of phenylene units linked together by C-C bonds that are between single- and double-bonded, and where $n$ corresponds to the number of phenylene units. In this work, we compare the response of the optical properties of different phenylene arrangements. We study linear chains (LPP), cyclic systems (CPPs), and non-conjugated cyclic systems with two hydrogenated phenylenes $\left(\mathrm{H}_{4}[\mathrm{n}] \mathrm{CPP}\right)$. Particularly, the systems of interest in this work are [6]LPP, [12]- and [6]CPP and $\mathrm{H}_{4}$ [6]CPP. This work combines Raman and infrared spectroscopies with absorption and fluorescence (one- and two-photon excitations) measured as a function of pressure up to maximum of about $25 \mathrm{GPa}$. Unprecedented crystallographic pressure-dependent results are shown on $\mathrm{H}_{4}[\mathrm{n}] \mathrm{CPP}$, revealing intramolecular $\pi-\pi$ interactions upon compression. These intramolecular interactions justify the $\mathrm{H}_{4}[\mathrm{n}] \mathrm{CPP}$ singular optical properties with increasing fluorescence lifetime as a function of pressure.
\end{abstract}

Keywords: linear and cyclic paraphenylene; pressure; vibrational spectroscopy; absorption; fluorescence

\section{Introduction}

Since the discovery of conducting polyacetylene [1], organic molecules and polymers with a $\pi$-conjugated aromatic backbone have been the subject of much scientific attention due to their ability to transport charge and efficiently interact with light. The aim of the field of organic optoelectronics is to develop a broad range of deformable optoelectronic materials and devices. $\pi$-conjugated molecules undergo a wide variety of transformations under high pressure, such as the formation of aggregates and polymers [2,3], an area of chemistry that has been only lightly explored because of the difficulties of definitive in situ characterisation $[4,5]$. On the other hand, pressure can be used to modulate the optic-electronic properties of materials $[6,7]$. 
Benzene is one of the most versatile building blocks in optoelectronic materials as it can be arranged to form one- and two-dimensional nanomaterials, i.e., fullerene and graphene. In addition, at the molecular level, benzene can assemble into linear or cyclic configurations, forming polyaromatic systems. Notable examples are linear chains of aromatic units linked to each other by single C-C bonds as in linear paraphenylenes ([n]LPPs), where $n$ is the number of phenyl units [8,9]. These materials have overtaken most of the field of optoelectronics materials and are used for applications in electronic and photo-electronic devices [10,11].

[n]LPPs in their ground state at ambient conditions have a non-planar configuration, presenting torsional angles between neighbouring phenyl units [12] and they become planar when a small pressure $(<1 \mathrm{GPa})$ is applied [13-16]. Compression also leads to a decrease in the intermolecular distances, which has led Hanfland et al. [6] to suggest that above 5 GPa permanent intermolecular links could be formed from interactions between the $\pi$-systems of the 1D planar chains [17]. The increase of in-plane conjugation, which occurs on planarisation, and the compression of the intermolecular distances, results in a redshift in the luminescence spectrum of LPPs with pressure $[6,13]$.

Cyclo[n]paraphenylenes ([n]CPPs) are formed by $n$ phenyl units connected to each other through their para positions and forming a cyclic unit. These were first synthesised in 2008. The unusual cyclic molecular symmetry of [n]CPPs offers a unique case of cyclic circulation of the $\pi$-electron density, or cyclic $\pi$-conjugation $[13,18,19]$, which confers on them distinct optical and electronic properties governed by their increasing strain with decreasing $n[20,21]$. The versatility of these systems in terms of aromaticity, unique size-dependent supramolecular properties and encapsulation of guest molecules leads to promising applications in materials science [22-27].

Due to the decrease in bending angle of the phenyl units with increasing size of the [n]CPPs, large [n]CPPs have features close to those of long [n]LPPs. However, large [n]CPPs are more energetic systems than long [n]LPPs on account of the strain generated in the cyclic systems by the deformation of planar phenyl units [28-31]. While in [n]LPPs the energy gap decreases with $n$ [32-34], the HOMO-LUMO gap of $[\mathrm{n}] \mathrm{CPPs}$ increases. However, their optical properties are dominated by the forbidden HOMO-LUMO transition [30,31,33,35-37].

Many different aspects of the ambient pressure chemistry of [n]CPPs have been already addressed in different laboratories [36]. In previous work, we explored high-pressure structural and mechanical properties of [n]CPPs [38-40]. The two smallest and most highly strained members of the series, [5]CPP and [6]CPP, polymerised at pressures between 5 and $6 \mathrm{GPa}$, whereas larger [n]CPPs are softer and remain in a monomeric state up to $10 \mathrm{GPa}$. [n]CPPs undergo ovalisation with compression at lower pressures with increasing sizes [40]. However, it is still unknown how the optical properties of [n]CPPs respond to deformation of the cycle.

Optical studies of molecular systems under high pressure allow us to correlate how intermolecular interactions and structural changes affect photo-physical properties without modifying their chemical composition $[41,42]$. In this work, we describe a systematic study on the electronic properties of [n]CPPs, providing a thorough link between [n]CPPs and [n]LPPs. We attempt to explore the mechanical response of [12]CPP, [6]CPP with a cyclic configuration, [6]LPP with linear conjugation and the tetrahydro [6]CPP $\left(\mathrm{H}_{4}[6] \mathrm{CPP}\right)$ with a non-conjugated cyclic configuration (see Figure 1). We present the first crystallographic study of a non-conjugated cycle $\mathrm{H}_{4}[6] \mathrm{CPP}$ as a function of pressure. Infrared and Raman spectroscopies are used to evaluate the reversibility or irreversibility of the pressure-induced structural changes in the conjugation backbone. UV-vis absorption and one- and two-photon excitation spectroscopies, also at high pressure, are used to reveal the striking optical properties of the different phenyl configurations. Pressure-dependent fluorescence lifetimes were also measured in some cases. As the evolution of [n]LPPs structural and optoelectronic properties with pressure is well understood $[6,13,16],[6]$ LPP will be used as a reference and to validate our measurements. 


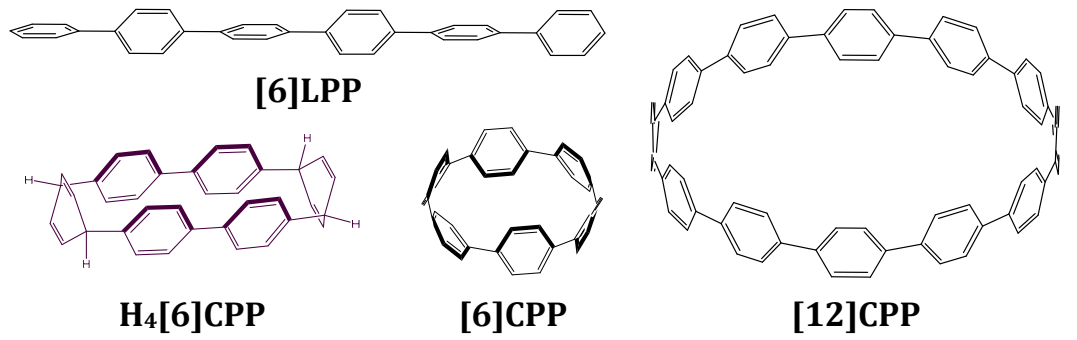

Figure 1. Scheme of the structures discussed in this work. [6]LPP stands for hexa linear paraphenylene, which is formed by six phenyl units linearly bonded to each other in their para position. $\mathrm{H}_{4}$ [6]CPP stands for tetrahydro hexa cycloparaphenylene and is configured by two diphenyl units linked to each other through two cyclohexadienes. [6]CPP stands for hexa-cycloparaphenylene and [12]CPP stands for dodeca-cycloparaphenylene. These are formed by $n$ phenyl units linked to each other in their para positions.

\section{Results}

\subsection{Effect of Pressure on the Crystal Structure}

In phase II benzene, the aromatic rings are arranged in a slipped-parallel configuration, i.e., the molecules lie on parallel planes [43]. The compression of benzene phase II induces a decrease in the intermolecular distances, resulting in covalent intermolecular bonds shorter than $3.0 \AA$ at around 30 GPa [43,44]. Through X-ray diffraction (XRD) experiments, Heimel et al. [17] found that LPPs' compression decreases intermolecular distances from about $4.045 \AA$ [45] to about $3.5 \AA$ at 6 GPa (see Table S1). Therefore, it is expected that the compression of [6]LPP would lead to the formation of intermolecular covalent linkages.

[12]CPP, whose diameter is about $1.65 \mathrm{~nm}$, has a crystal structure characterised by a T-shaped arrangement of the molecules, which strongly impedes $\pi-\pi$ intermolecular contact formation (see Table S2). [6]CPP, with a diameter of about $0.88 \mathrm{~nm}$, is polymorphic and either forms tubular or herringbone arrangements [46]. Pressure-dependent XRD studies of these systems are beyond the scope of this work.

In this work, we conduct a pressure-dependent X-ray diffraction study on a single crystal of $\mathrm{H}_{4}[6] \mathrm{CPP}$ in order to relate structural changes with the spectroscopic changes observed upon compression. Table S3 reports all the experimental details. The crystal structure of $\mathrm{H}_{4}[6] \mathrm{CPP}$ was investigated using single-crystal X-ray diffraction between ambient pressure and 4.59 GPa. $\mathrm{H}_{4}[6] \mathrm{CPP}$ crystallises in the monoclinic space group $P 2_{1} / c$, with four molecules per unit cell and one molecule in the asymmetric unit. The effect of pressure on the unit cell parameters is shown in Figure $2 \mathrm{a}$. The cell axes and volume smoothly decrease with each step in the pressure series, showing the absence of any first-order phase transitions. The $a, b$ and $c$-axes compress by $3.1 \%, 13.4 \%$ and $8.6 \%$, respectively, up to 4.59 GPa.

The molecular structure is shown in Figure $2 \mathrm{~b}$. The closest intramolecular distance between phenyl units under ambient conditions is formed between the phenyl rings containing C13 and C25: the centroid-centroid distance is $3.79 \AA$ and the angle between the planes is $10.59(9)^{\circ}$. At $4.59 \mathrm{GPa}$, these geometries change to $3.33 \AA$ and $6.1(7)^{\circ}$, respectively. In the same pressure range, the length of the molecule as measured by the distance between the centroid of the hexadiene rings based on C1 and C19, undergoes a modest change from 10.65 to $10.69 \AA$ such that the molecule becomes more oblate overall.

The molecules are packed in a distorted body-centred cubic topology in which a central reference molecule is surrounded in a plane by six others, with four additional molecules in the planes above and below, giving an overall molecular coordination number of 14 (Figure 3a). This arrangement persists throughout the pressure range studied (Table S4 lists extended structural information). An analysis 
of the intermolecular energies is shown in Table 1, where colours shown for each contact are also indicated in the molecular centroids of Figure $3 a$.

a)

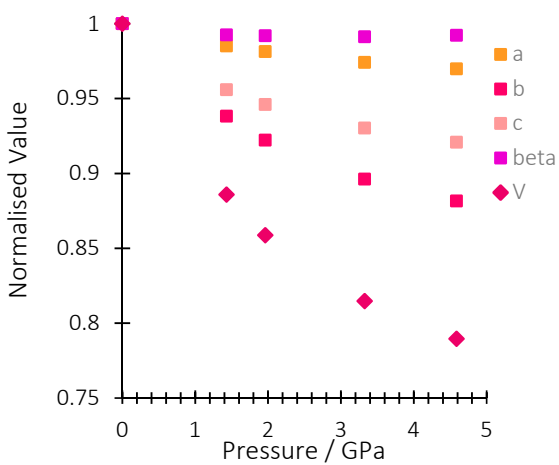

b)

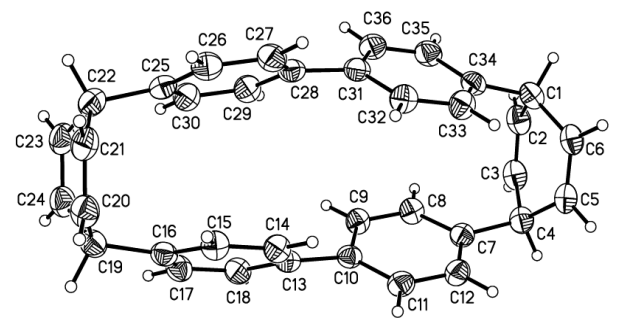

Figure 2. (a) Variation of the normalised lattice parameters and unit cell volume of $\mathrm{H}_{4}[6] \mathrm{CPP}$ as a function of pressure. (b): $\mathrm{H}_{4}$ [6]CCP structure in the crystal at ambient pressure and $298 \mathrm{~K}$. Ellipsoids are shown with $30 \%$ probability surfaces.

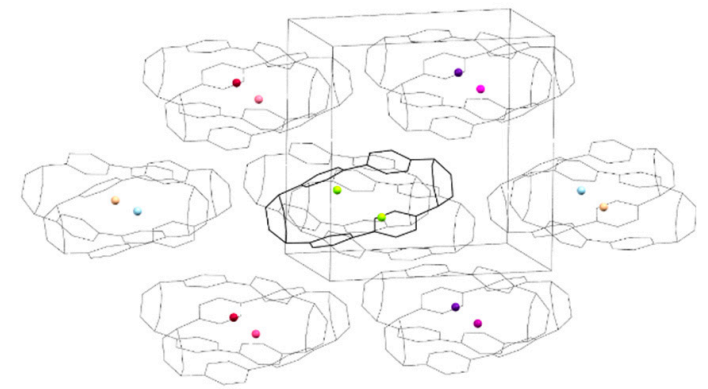

a)
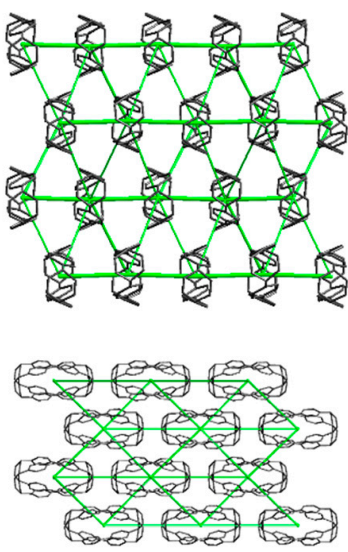
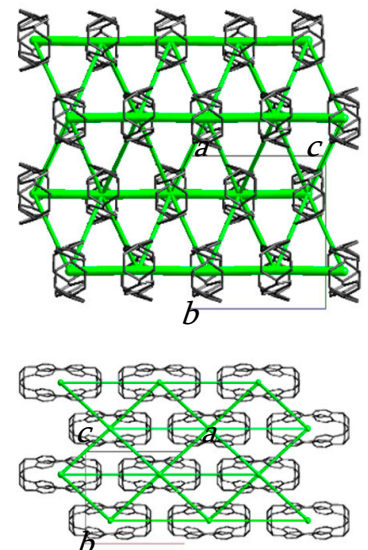

b)

Figure 3. (a) Crystal packing in $\mathrm{H}_{4}$ [6]CPP. The molecular centroids are shown as small spheres where the colours correspond to the molecular contact energies listed in Table 1. (b) Dispersion energy framework of the $\mathrm{H}_{4}$ [6]CPP structure at $0 \mathrm{GPa}$ (left) and $4.59 \mathrm{GPa}$ (right) viewed along the $a$-axis (top) and $c$-axis (bottom). The thickness of the struts is proportional to the magnitude of the energy. Hydrogen atoms are removed for clarity.

Table 1. Interactions in the first coordination sphere of $\mathrm{H} 4\{6\} \mathrm{CPP}$ at 0 and $4.59 \mathrm{GPa}$. All energies are in $\mathrm{kJ} \mathrm{mol}^{-1}$. Color coding correspond to the dummy points marked in Figure $3 \mathrm{a}$.

\begin{tabular}{cccccccccccc}
\hline & & \multicolumn{2}{c}{ Electrostatic } & \multicolumn{2}{c}{ Polarisation } & \multicolumn{2}{c}{ Dispersion } & \multicolumn{2}{c}{ Repulsion } & \multicolumn{2}{c}{ Total } \\
\cline { 3 - 14 } & Pressure/GPa & $\mathbf{0}$ & $\mathbf{4 . 5 9}$ & $\mathbf{0}$ & $\mathbf{4 . 5 9}$ & $\mathbf{0}$ & $\mathbf{4 . 5 9}$ & $\mathbf{0}$ & $\mathbf{4 . 5 9}$ & $\mathbf{0}$ & $\mathbf{4 . 5 9}$ \\
\hline $\mathbf{2}$ & $-\mathrm{x}, \mathrm{y}+1 / 2,-\mathrm{z}+1 / 2$ & -6.9 & -25.1 & -1.4 & -2.9 & -35.9 & -66.2 & 20.4 & 90.5 & -27.1 & -30.4 \\
$\mathbf{2}$ & $-\mathrm{x}, \mathrm{y}+1 / 2,-\mathrm{z}+1 / 2$ & -6.5 & -22.0 & -1.4 & -2.5 & -30.8 & -54.1 & 15.8 & 70.0 & -24.9 & -29.0 \\
\hline $\mathbf{2}$ & $\mathrm{x},-\mathrm{y}+1 / 2, \mathrm{z}+1 / 2$ & -0.1 & -3.3 & -0.1 & -0.3 & -6.7 & -14.3 & 1.8 & 17.3 & -4.8 & -5.6 \\
$\mathbf{2}$ & $\mathrm{x},-\mathrm{y}+1 / 2, \mathrm{z}+1 / 2$ & -8.3 & -51.5 & -0.6 & -1.7 & -71.8 & -143.5 & 36.4 & 197.2 & -49.3 & -58.9 \\
$\mathbf{2}$ & $\mathrm{x},-\mathrm{y}+1 / 2, \mathrm{z}+1 / 2$ & -4.6 & -15.0 & -0.8 & -2.2 & -25.9 & -45.5 & 16.8 & 74.7 & -10.7 & -11.0 \\
\hline $\mathbf{1}$ & $-\mathrm{x},-\mathrm{y},-\mathrm{z}$ & -2.5 & -29.1 & -0.4 & -3.1 & -13.1 & -66.2 & 3.8 & 91.1 & -12.0 & -34.8 \\
$\mathbf{1}$ & $-\mathrm{x},-\mathrm{y},-\mathrm{z}$ & -6.8 & -9.5 & -1.3 & -1.2 & -31.5 & -33.3 & 17.2 & 30.5 & -25.0 & -21.1 \\
$\mathbf{1}$ & $-\mathrm{x},-\mathrm{y},-\mathrm{z}$ & -3.6 & -10.0 & -0.5 & -1.5 & -16.1 & -35.4 & 5.9 & 34.1 & -14.6 & -21.5 \\
$\mathbf{1}$ & $-\mathrm{x},-\mathrm{y},-\mathrm{z}$ & -8.9 & -33.0 & -2.1 & -4.1 & -47.6 & -83.0 & 29.1 & 119.9 & -34.4 & -36.1 \\
\hline
\end{tabular}


The pattern of intermolecular contacts is shown using energy frameworks in Figure 3b. The lack of framework struts in the $b$-direction is presumably the reason why the crystal experiences most compression along this direction (Figure 2a). The strongest interaction is a non-specific dispersion contact formed by alignment of the long axes of two molecules; thus, at $-50 \mathrm{~kJ} \mathrm{~mol}^{-1}$, the energy of this interaction is like a moderately strong hydrogen bond. The weakest interactions (the pale blue contact with $-10.7 \mathrm{~kJ} \mathrm{~mol}^{-1}$ and the yellow contact with $-4.8 \mathrm{~kJ}$ mol- ${ }^{1}$ ) are built along the $a$-axis, where the facing phenylene ring fragments from different molecules interact with each other through their respective double bonds. These interactions are also the shortest, with the ring centroids being separated by $4.24 \AA$ at ambient pressure and $3.54 \AA$ at 4.59 GPa. The variation of other intra- and intermolecular ring and centroid distances are shown in Figure 4. The fact that at $4.59 \mathrm{GPa}$ the shortest intramolecular distance is $3.33 \AA$ while the shortest intermolecular distance is still $3.54 \AA$ suggests that further compression could lead to the formation of covalent intramolecular links.

\begin{tabular}{ccc}
\hline Site & $\begin{array}{c}\text { 0 GPa distance } \\
(\AA)\end{array}$ & $\begin{array}{c}\text { 4.59 GPa distance } \\
(\AA)\end{array}$ \\
\hline $\mathrm{r}_{1}-\mathrm{r}_{4}$ & 10.650 & 10.687 \\
$\mathrm{r}_{2}-\mathrm{r}_{6}$ & 3.792 & 3.327 \\
$\mathrm{r}_{3}-\mathrm{r}_{5}$ & 3.803 & 3.343 \\
$\mathrm{R}_{1}-\mathrm{R}_{2}$ & 6.297 & 5.796 \\
$\mathrm{R}_{3}-\mathrm{R}_{4}$ & 6.297 & 5.796 \\
$\mathrm{R}_{1}-\mathrm{R}_{4}$ & 10.630 & 10.059 \\
$\mathrm{R}_{2}-\mathrm{R}_{3}$ & 10.630 & 10.059 \\
$\mathrm{R}_{2}-\mathrm{R}_{4}$ & 14.469 & 13.576 \\
$\mathrm{R}_{1}-\mathrm{R}_{3}$ & 9.796 & 9.234 \\
$\mathrm{r}_{1}-\mathrm{r}_{4}$ & 4.238 & 3.538 \\
\hline
\end{tabular}

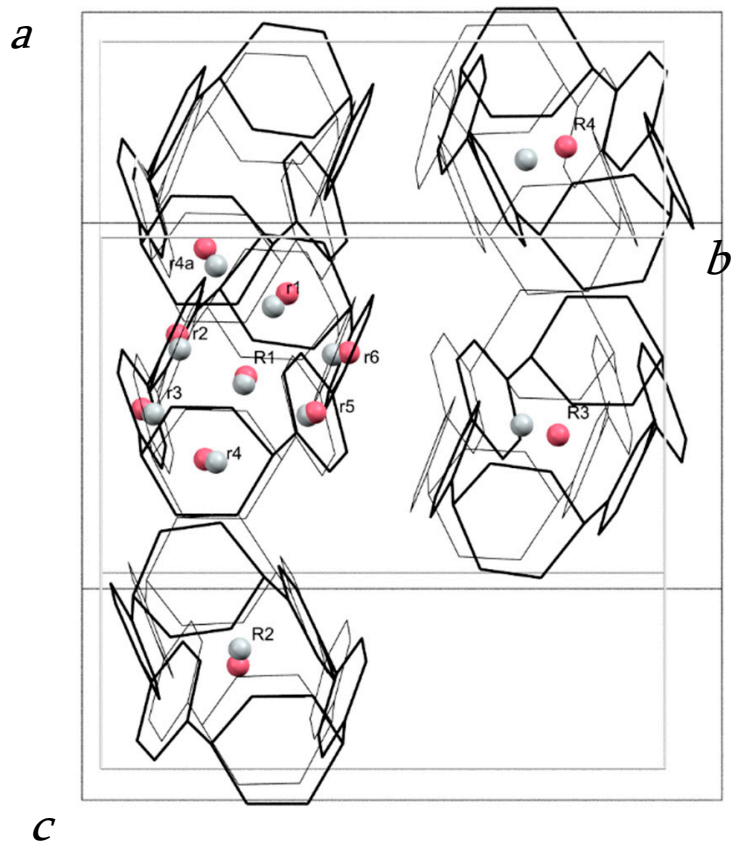

Figure 4. (left) Table of centroid-centroid distances in the $\mathrm{H}_{4}[6] \mathrm{CPP}$ structure at 0 and $4.59 \mathrm{GPa}$. (right) Structure of $\mathrm{H}_{4}$ [6]CPP viewed along a* at ambient pressure (black wireframes) and at $4.59 \mathrm{GPa}$ (grey wireframes), indicating intramolecular and intermolecular distances calculated between centroids (pink for $0 \mathrm{GPa}$ and grey for $4.59 \mathrm{GPa}$ ). Hydrogen atoms are removed for simplification. Molecular centroids are indicated with $R_{1}, R_{2}$; the centroids of individual rings are labelled $r_{1}, r_{2}$.

\subsection{FTIR}

It has been demonstrated that the most significant spectral changes occurring in paraphenylenes as a function of pressure are seen in the $\mathrm{C}-\mathrm{H}$ stretching modes as they are sensitive to the $\mathrm{sp}^{3}$ or $\mathrm{sp}^{2}$ hybridisation of carbon $[47,48]$. The clearest example is provided by the pressure-induced polymerisation of benzene itself in which the $\mathrm{C}-\mathrm{H}$ stretching from aromatic benzene at around $3000-3200 \mathrm{~cm}^{-1}$ in the IR spectrum vanishes in decompression to $27 \mathrm{GPa}$ and is replaced by a C-H stretching band characteristic of saturated $C\left(\mathrm{sp}^{3}\right)$ at around $2900 \mathrm{~cm}^{-1}[47,48]$. Therefore, this section will mainly discuss this high-frequency region, although data have been collected in the frequency range between 500 and $3200 \mathrm{~cm}^{-1}$ and are available in the Supporting Information (Figures S1-S4). In Figure 5, the FTIR spectra in the $2800-3300 \mathrm{~cm}^{-1}$ region at selected pressures are shown in order of increasing cyclic conjugation: [6]LPP, $\mathrm{H}_{4}[6] \mathrm{CPP},[12] \mathrm{CPP}$ and [6]CPP. 


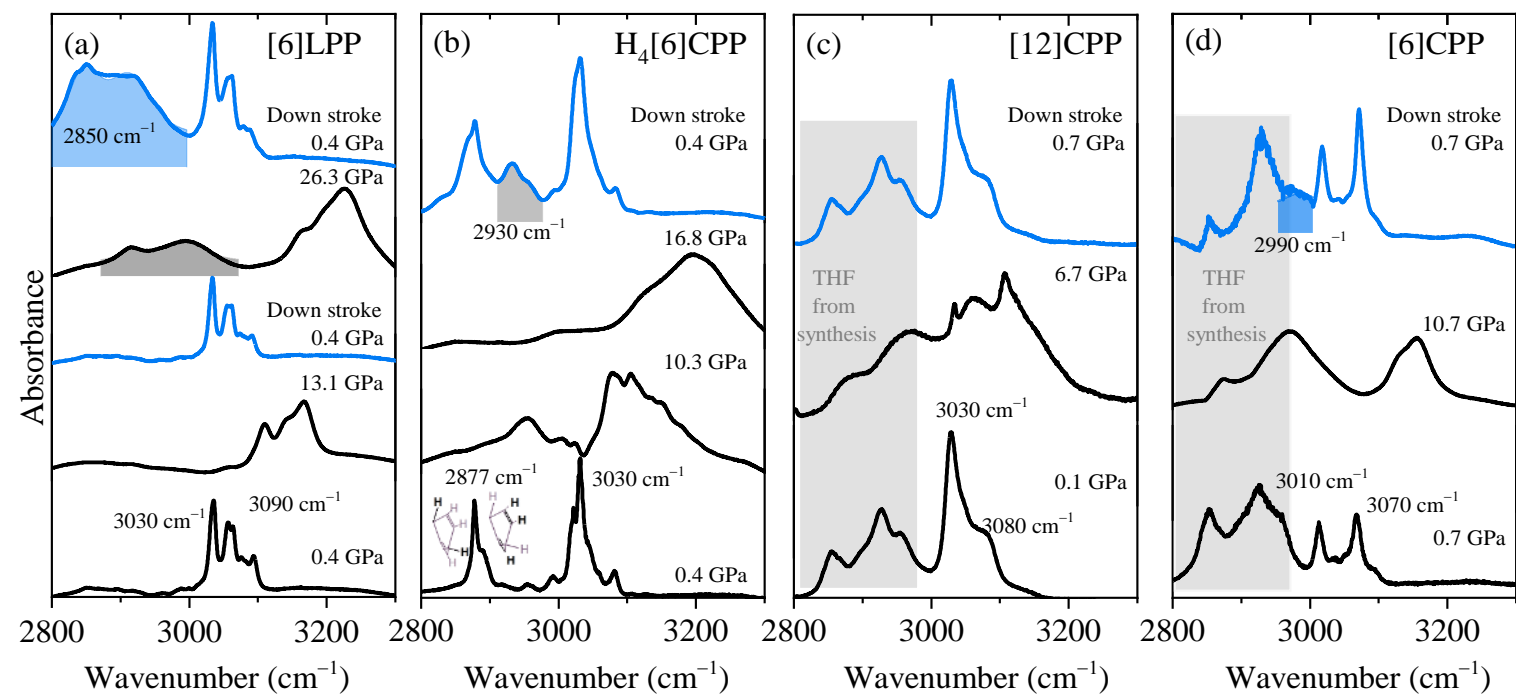

Figure 5. Infrared spectra at selected pressures of the different crystalline compounds measured using $\mathrm{KBr}$ as the pressure transmitting media. Blue spectra correspond to the product obtained in decompression and the product band is highlighted: (a) [6]LPP; (b) $\mathrm{H}_{4}[6] \mathrm{CPP}$; (c) [12]CPP; and (d) [6]CPP.

FTIR experiments were performed to explore the possibility of pressure-induced reactivity. In addition, IR experiments were used to calibrate the frequencies of the vibrational modes as a function of pressure and to use them as an internal pressure gauge in the fluorescence measurements. For each of the phenylene systems, one or two polycrystalline samples were investigated using ruby fluorescence as a pressure marker [49].

In Figure 5a, we show the FTIR spectra at different pressures for [6]LPP in the region corresponding to the $\mathrm{C}-\mathrm{H}$ stretching modes. With increasing pressure, there is a change in the $\mathrm{C}-\mathrm{H}$ profile that can be related to the change from a twisted to a planar configuration (see Figure S1). When the maximum pressure reached is below $15 \mathrm{GPa}$, decompression re-establishes the initial [6]LPP $\mathrm{D}_{2}$ configuration. However, if [6]LPP is compressed above $25 \mathrm{GPa}$, then a saturated C-H stretching mode at around $2900 \mathrm{~cm}^{-1}$ appears in the infrared spectrum. This new band rapidly grows to become the most intense feature of the spectrum after the pressure is released. These results indicate that compression at around $25 \mathrm{GPa}$ can induce the loss of aromaticity within the phenyl units through the formation of intermolecular linkages.

Figure $5 b$ shows the pressure-dependent FTIR of $\mathrm{H}_{4}[6] \mathrm{CPP}$. At the lowest pressure, the $\mathrm{H}_{4}[6] \mathrm{CPP}$ high-frequency spectrum is characterised by two sets of bands: one at lower frequencies (around $2887 \mathrm{~cm}^{-1}$ and $2900 \mathrm{~cm}^{-1}$ ) that correspond to C-H stretching modes of saturated carbons and of those from the olefinic C-H bonds of the cyclohexadiene units, respectively. Bands at $3030 \mathrm{~cm}^{-1}$ correspond to the $\mathrm{C}-\mathrm{H}$ stretches of the phenylene units. As seen in Figure 5b, compression of $\mathrm{H}_{4}$ [6]CPP leads to an intensity increase of the $\mathrm{C}-\mathrm{H}$ stretching band derived from the phenylene moieties, which could be interpreted by the pressure-induced strengthening of the $\pi-\pi$ interactions as we know that the intramolecular distances are decreasing in compression. Interestingly, decompression from 17 GPa shows the irreversibility of the process as there is a new contribution around $2930 \mathrm{~cm}^{-1}$ that is consistent with an increase in $\mathrm{C}-\mathrm{H}$ stretching involving $\mathrm{C}$ with higher $\mathrm{sp}^{3}$ character. Such reactivity might be induced by intra- or intermolecular reactivity through the phenylene units, or through the cyclohexadiene units, respectively. The shorter intramolecular distances of $3.33 \AA$ at $4.59 \mathrm{GPa}$ and obtained in the XRD results indicate that intramolecular reactivity might be favoured in this case.

It has been reported that compression of [12]CPP induces the deformation of the cycle towards a more oval configuration, creating shorter and longer diameters [7,40]. The onset of ovalisation is below 1 GPa [40]; however, the FTIR spectra presented in Figure 5c show that compression within 
the oval regime does not seem to affect the $\mathrm{sp}^{2}$ framework as the $\mathrm{C}-\mathrm{H}$ stretching modes broaden and upshift while maintaining their band shapes. After pressure is released, the spectrum is identical to that of the pristine sample.

The compression of tubular [6]CPP above 6 GPa causes a permanent deformation of the cycle that could lead to the formation of intermolecular covalent linkages [39]. Figure $5 \mathrm{~d}$ shows that at $10 \mathrm{GPa}$, the C-H stretching modes of the aromatic phenyl units upshift and broaden but their overall profile persists. After decompression, a new contribution at lower frequencies appears at around $2990 \mathrm{~cm}^{-1}$, indicating the irreversibility of the compression cycle. This band would correspond to a contribution from more saturated carbons and could be explained by a pressure-induced polymerisation.

The pressure shift of aromatic C-H stretching has been estimated for all the systems and compared with that of benzene in Table 2. As seen in the table, benzene and [6]LPP show similar values, which in increasing order are as follows: benzene, [6]LPP, [6]CPP, $\mathrm{H}_{4}$ [6]CPP and [12]CPP. It is interesting that [12]CPP is the one with largest coefficient as it is the only one showing a reversible response to compression within the explored pressure range.

Table 2. Interceptions and pressure shift of the $\mathrm{C}-\mathrm{H}$ stretching bands from phenyl contributions.

\begin{tabular}{ccc}
\hline SYSTEM & $\boldsymbol{\omega}_{\mathbf{0}} \mathbf{( \mathbf { c m } ^ { - 1 } )}$ & $\mathbf{A}, \mathbf{( c m}^{\mathbf{- 1}} \mathbf{G P a}^{-\mathbf{1}} \mathbf{)}$ \\
\hline Benzene [44] & 2990 & $4.7 \pm 0.2$ \\
[6]LPP & $3030 / 3090$ & $5.5 \pm 0.4$ \\
$\mathrm{H}_{4}$ [6]CPP & 3030 & $8.0 \pm 0.8$ \\
[12]CPP & $3030 / 3080$ & $9.0 \pm 0.8$ \\
[6]CPP & $3010 / 3070$ & $6.8 \pm 0.5$ \\
\hline
\end{tabular}

\subsection{Raman Spectroscopy}

Pressure-induced intramolecular interactions can be responsible for the general increase in the positions of the Raman bands. It has already been established that there is a common Raman response that reveals structural ovalisation of [n]CPP. The deformation of the cycle is revealed by a change of the rate of frequency shift as a function of pressure [40]. The most intense Raman bands appear in the $1560-1600 \mathrm{~cm}^{-1}$ range, having originated from symmetric vibrations arising from collective C-C stretching modes of the benzenoid rings along the transversal direction. Different $\mathrm{sp}^{2}$ carbon systems as single-wall carbon nanotubes or graphite also present C-C stretching modes in the 1560-1600 $\mathrm{cm}^{-1}$ region; therefore, we will refer to them as ' $\mathrm{G}_{\mathrm{A1g}}$ ' modes ( $\mathrm{G}$ is aligned to graphite, which also shows this mode, and $\mathrm{A}_{1 \mathrm{~g}}$ to the symmetry) [7]. In this work, we measure the Raman spectra of selected powdery systems within an anvil cell at selected pressures. The Raman shift GA 1 [7] is shown for all of the systems in Figure 6 (see also Figures S5-S8 for raw data and analysis of the decompressed sample). As in the compression of phase II of benzene [45], and in line with former results, the $\mathrm{GA}_{1 \mathrm{~g}}$ mode of [6]LPP linearly upshifts [16,50]. The pressure at which the [n]CPPs change the slope and, thus, the cycle, becomes oval is higher the more strained and rigid the cycle is, in agreement with the change in slope at around $5 \mathrm{GPa}$ in [6]CPP and below $1 \mathrm{GPa}$ in [12]CPP [40]. In the case of the non-conjugated cycloparaphenylene $\mathrm{H}_{4}[6] \mathrm{CPP}$, the C-C stretching mode from the aromatic units of $\mathrm{H}_{4}[6] \mathrm{CPP}$ linearly upshift to approximately $8 \mathrm{GPa}$, where there is a change in slope. Figure $6 \mathrm{~b}$ shows the described deformations for the conjugated and non-conjugated CPP.

Equation (1) describes approximate piecewise linear trends in the Raman frequencies:

$$
\begin{array}{ll}
\omega_{\mathrm{i}}(\mathrm{P})=\omega_{\mathrm{i}}(0)+\mathrm{A}_{, \mathrm{i}} \mathrm{P}, & \text { if }\left(\mathrm{P}<P_{\text {oval }}^{n}\right) \\
\omega_{\mathrm{i}}(\mathrm{P})=\omega_{\mathrm{i}}(0)+\mathrm{A}_{, \mathrm{i}} P_{\text {oval }}^{n}+\mathrm{B}_{, \mathrm{i}}\left(\mathrm{P}-P_{\text {oval }}^{n}\right), & \text { if }\left(\mathrm{P}>P_{\text {oval }}^{n}\right)
\end{array}
$$

$\mathrm{A}_{, \mathrm{i}}$ and $\mathrm{B}_{, \mathrm{i}}$ correspond to the pressure coefficients at pressures below and above $P_{\text {oval }}^{n}$ (ovalisation pressure), respectively, and $\omega_{i}(0)$ is the Raman shift at ambient pressure. Thus, for each band we have three parameters, $\left(\omega_{i}(0), A_{, i}\right.$ and $\left.B_{, i}\right)$ and these are compared in Table 3 . The similar of $A_{. i}$ 
for benzene [45], [6]LPP and $\mathrm{H}_{4}$ [6]CPP demonstrate their similar physical, chemical, and structural response to compression. In previous work, we demonstrated that the similar large values of the $A$ coefficients for CPPs are related to the deformation of the cycle and, therefore, of the phenyl units [40]. Moreover, the $\mathrm{H}_{4}[6] \mathrm{CPP} \mathrm{C}=\mathrm{C}$ stretching mode corresponding to the cyclohexadiene units linearly upshift to $10 \mathrm{GPa}$ while not showing a change in slope.

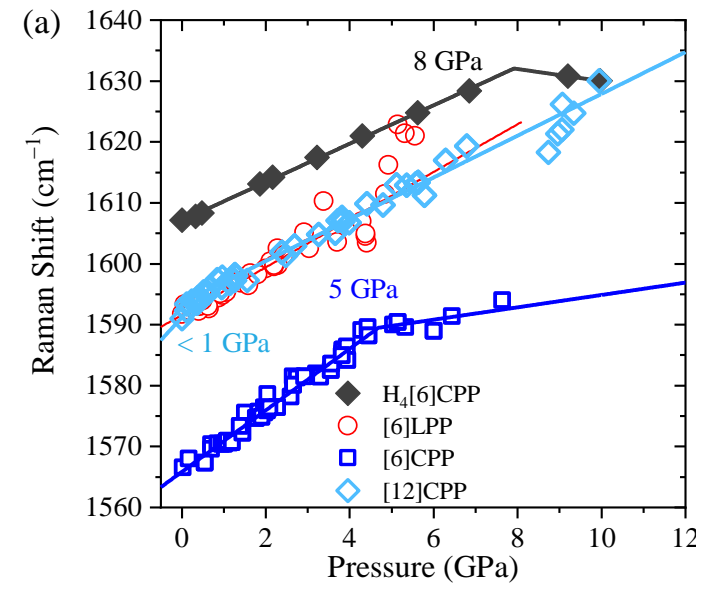

(b)

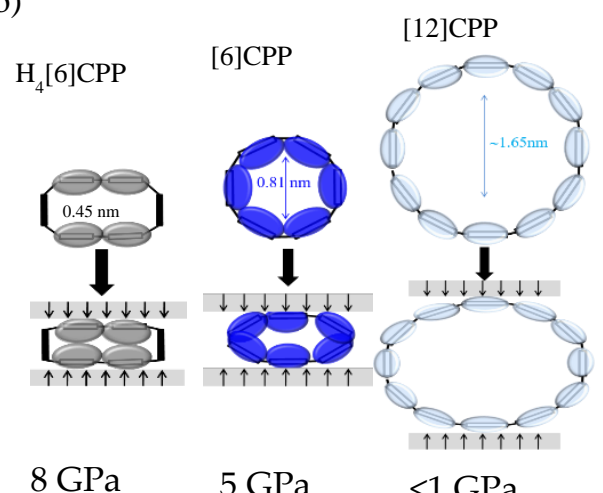

Figure 6. (a) Pressure dependence of the Raman shifts $\mathrm{GA}_{1 \mathrm{~g}}$ mode of the different crystalline compounds with no pressure transmitting media. Solid lines correspond to the data fitting to Equation (1). (b) Scheme representing deformation of the cycles at $P_{\text {oval }}$.

Table 3. Experimental interceptions and pressure coefficients of the linear variation with pressure of the $\mathrm{G}$ bands for each system before $(\mathrm{A})$ and after $(\mathrm{B})$ the ovalisation pressure $\left(P_{\text {oval }}\right)$.

\begin{tabular}{|c|c|c|c|c|c|c|c|c|}
\hline \multirow[b]{2}{*}{ SYSTEM } & \multirow[b]{2}{*}{$\begin{array}{l}\text { Diameter } \\
(\mathrm{nm})\end{array}$} & \multirow[b]{2}{*}{$\begin{array}{l}P_{\text {oval }} \\
\text { (GPa) }\end{array}$} & \multicolumn{3}{|c|}{$\mathrm{GA}_{1 \mathrm{~g}}$} & \multicolumn{3}{|c|}{$\mathrm{GE}_{2 \mathrm{~g}}$} \\
\hline & & & $\begin{array}{c}\omega_{0} \\
\left(\mathrm{~cm}^{-1}\right)\end{array}$ & $\underset{\left(\mathrm{cm}^{-1} \mathrm{GPa}^{-1}\right)}{\mathrm{A}}$ & $\begin{array}{c}\mathrm{B} \\
\left(\mathrm{cm}^{-1} \mathrm{GPa}^{-1}\right)\end{array}$ & $\begin{array}{c}\omega_{0} \\
\left(\mathrm{~cm}^{-1}\right)\end{array}$ & $\underset{\left(\mathrm{cm}^{-1} \mathrm{GPa}^{-1}\right)}{\mathrm{A}}$ & $\begin{array}{c}\mathrm{B} \\
\left(\mathrm{cm}^{-1} \mathrm{GPa}^{-1}\right)\end{array}$ \\
\hline [6]LPP & - & - & 1592 & $3.9 \pm 0.3$ & - & - & - & - \\
\hline $\mathrm{H}_{4}[6] \mathrm{CPP}$ & 0.45 & 9 & 1610 & $3.1 \pm 0.1$ & $-1.0 \pm 0.1$ & 1658 & $3.2 \pm 0.1$ & - \\
\hline [12]CPP & $1.65[51]$ & 1 & 1595 & $7.0 \pm 2.0$ & $3.4 \pm 0.1$ & 1602 & $9.0 \pm 2.0$ & $3.9 \pm 0.1$ \\
\hline
\end{tabular}

\subsection{Absorption and Fluorescence at Low Pressures}

In linear paraphenylenes, the absorption spectrum is a consequence of the allowed HOMO-LUMO absorption. The HOMO-LUMO band gap in [n]LPPs decreases with the lengthening of the conjugation that occurs as $n$ increases, but it can also be enhanced by the decrease of inter-phenyl torsional angles [53,54]. Thus, the absorption spectrum of [6]LPP can be fitted to three different vibronic contributions, the 0-0, 0-1 and 0-2 as shown in Figure 7a. [6]LPP is a good light emitter, with a lifetime value of $0.78 \mathrm{~ns}$ [55]. The PL spectrum of [6]LPP is characterised by a vibronic progression with three main contributions at 422,447 and $467 \mathrm{~nm}$. The highest energy band at $422 \mathrm{~nm}$ is the $0-0$ transition, followed by $0-1$ and $0-2$.

In the case of the [n]CPPs, the complex interplay of symmetry, $\pi$-conjugation, conformational distortion and bending strain controls the photophysical properties. These molecules have high optical absorbance in the blue spectral region that increases with the ring size; however, the absorption maxima (at $\sim 340 \mathrm{~nm}$ ) are independent of the ring size as seen in the absorption spectra of [12]- and [6]CPP shown in Figure $7 b, c$, respectively. Vertical absorption happens between the HOMO-1/HOMO-2 to $\mathrm{LUMO}, \mathrm{HOMO}$ to $\mathrm{LUMO}+1 / \mathrm{LUMO}+2$ and $\mathrm{S}_{2}$ and $\mathrm{S}_{3}$ states, respectively, which are degenerate (or almost-degenerate in [6]CPP) by symmetry [22]. 

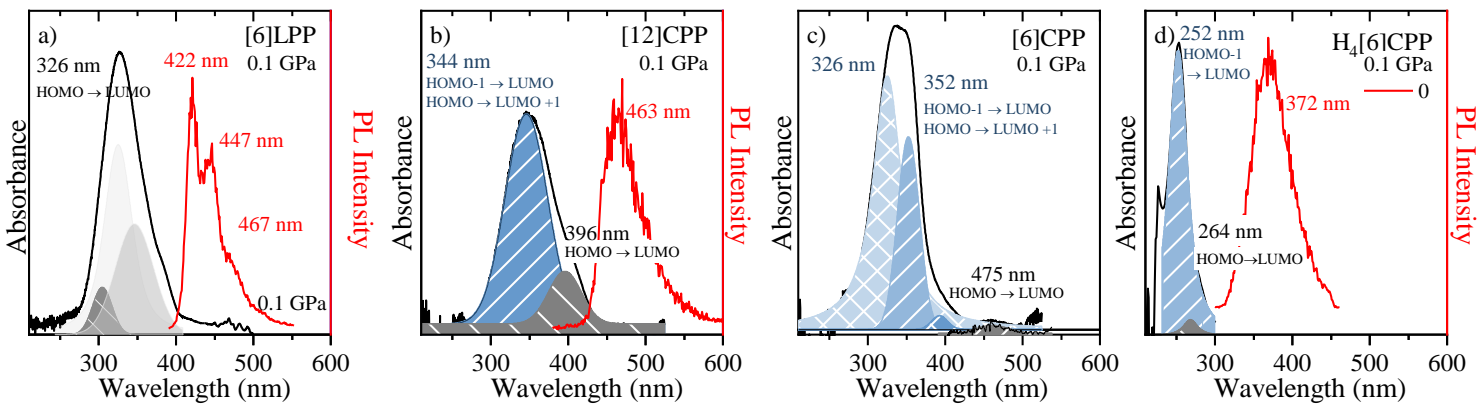

Figure 7. UV-vis absorption and emission spectra are marked as black and red, respectively. (a) [6]LPP; (b) [12]CPP; (c) [6]CPP; and (d) $\mathrm{H}_{4}$ [6]CPP. All samples were measured as powdered. HOMO-LUMO transitions are marked. [6]CPP emission is not allowed by selection rules being this why there is not PL intensity indicated (see text).

The absorption spectra of both CPPs contain shoulder-like bands at around $396 \mathrm{~nm}$ in [12]CPP and $475 \mathrm{~nm}$ in [6]CPP, which correspond to the HOMO-LUMO absorption $\mathrm{S}_{0}$ to $\mathrm{S}_{1}$ [56]. By contrast to the LLPs, a higher value of $n$ implies a larger HOMO-LUMO band gap [30,31]. Although these HOMO-LUMO transitions are forbidden by symmetry, the imperfect geometry of CPPs leads to small perturbations in the electronic wave function that result in a small but non-zero oscillator strength and the presence of HOMO-LUMO absorption at low intensity [55]. The inhomogeneous broadening of the [6]LPP and [n]CPP spectra is due to conformational structural variations related to irregular variations of the dihedral angles [30,31,55].

A peculiar feature of cycloparaphenylenes is their unusual optoelectronic behaviour as a function of molecular size. Specifically, the emission and quantum efficiency diminishes, which lengthens fluorescence lifetimes for smaller $n$ [35]. This diminution in quantum efficiency implies that the [6]CPP $\mathrm{S}_{1}$ state is not fluorescent [57]. We find that the emission of [12]CPP shows a maximum at $463 \mathrm{~nm}$ and lifetime of $2.6 \mathrm{~ns}$, which is in agreement with previous results [35]. The explanation for the observation of this emission from the forbidden $S_{1}$ state has been approached through a variety of hypotheses: phonon-assisted transitions [36]; efficient fluorescence in large CPP hoops to a broken Condon approximation due to exciton self-trapping [55]; vibrational intensity borrowing from the higher states [58]; Jahn-Teller distortion effects due to coupling to circle-to-oval vibrational modes breaking the selection rules [37]; and strong exciton-vibration couplings [36,55]. None of these occur in the small molecules, which remain inefficient emitters [55].

While the $S_{0} \rightarrow S_{1}$ transition is forbidden in the linear response, it can be probed by nonlinear spectroscopies such as two-photon absorption [36]. In this work, one-photon (OP) and two-photon (TP) absorption were tested for both [12]- and [6]CPP. Emission is a one-photon transition and its activity is not affected by the excitation mechanism (OP or TP). Thus, in the case of [12]CPP, no significant change in the PL spectrum is observed, which is in agreement with previous results [30,36]. However, in the [6]CPP case, no fluorescence was detected.

The absorption and emission spectra of $\mathrm{H}_{4}[6] \mathrm{CPP}$ are presented in Figure $7 \mathrm{~d}$. The absorption $\mathrm{UV}$-vis spectrum was measured in a $\mathrm{KBr}$ matrix. The band profile analysis of the absorption spectrum shows that it is formed from two contributions. To understand the origin of these two contributions, we conducted TD-DFT B3LYP/6-31G $(\mathrm{d}, \mathrm{p})$ calculations on the optimised B3LYP/6-31G $(\mathrm{d}, \mathrm{p})$ structure of a single molecule. These calculations show that there is only one absorption allowed that would correspond to the maximum of the absorption band at $252 \mathrm{~nm}$ corresponds mainly to the HOMO-1 to LUMO/HOMO to LUMO+1 transition with an oscillator strength of 0.91 . On the other hand, the HOMO-LUMO absorption is formally symmetry-forbidden absorption (see supporting information for more information); however, we relate the experimentally observed band at $264 \mathrm{~nm}$ to this HOMO-LUMO transition. As in the case of [12]CPP, in symmetry distortion of $\mathrm{H}_{4}[6] \mathrm{CPP}$ should be responsible for perturbing symmetry rules, which explains why the HOMO-LUMO absorption 
is observed. On the other hand, the fluorescence spectrum at low pressure was measured through one-photon excitation within the diamond anvil cell at $0 \mathrm{GPa}$. As seen in Figure $7 \mathrm{~d}, \mathrm{H}_{4}[6] \mathrm{CPP}$ is a strong fluorophore whose lifetime is $10 \mathrm{~ns}$, which is lower than that found for diphenyl units at 16.0 ns [55] as expected for systems with larger $\pi$-conjugation.

\subsection{Optical Absorption in Compression}

The UV-visible absorption spectra in the region of 370-500 $\mathrm{nm}$ were measured for all the samples at selected pressures. Powdered samples were diluted with $\mathrm{NaBr}$ and loaded into the gasket chamber together with a ruby chip, whose fluorescence shift was used as pressure marker [48]. As reference in the absorption measurements, the sample chamber was loaded with $\mathrm{NaBr}$ and its UV-vis transmission spectrum was measured.

UV-vis measurements of [6]LPP up to $12.5 \mathrm{GPa}$ (Figure 8a) show a broadening of the absorption bands with pressure, accompanied by new contributions that appear at lower energy (marked in green). Computational work demonstrates that the band gap decreases with the decreasing angle between neighbouring phenyl units [49]. With support from TD-DFT calculations (Figure S10), additional absorption bands at lower energy can thus be assigned to the planar conformer. The absorption intensity rapidly decreases with compression although spectra could not be measured beyond $12.5 \mathrm{GPa}$ as seen in Figure 8a.

The $\mathrm{H}_{4}[6] \mathrm{CPP}$ pressure-dependent absorption measurements were done using $\mathrm{H}$-silicon carbide as anvils, which limits the spectral range to $300 \mathrm{~nm}$ and above, and only part of the $S_{0} \rightarrow S_{1}$ absorption $252 \mathrm{~nm}$ could be detected. In Figure 8b, the absorption edges at different pressures are presented.
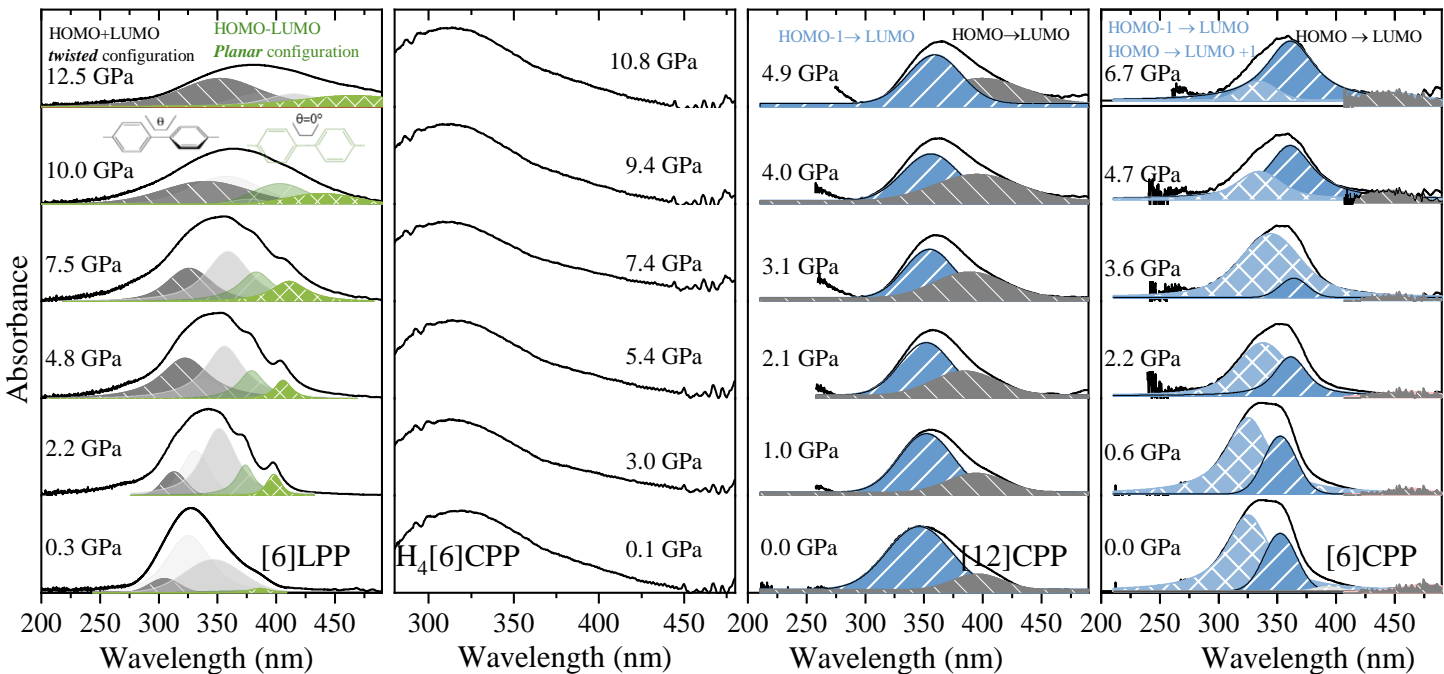

Figure 8. Absorption spectra of powdered samples in the near-UV-vis spectrum at selected pressures (diamond absorption has been subtracted). (a) [6]LPP: different contributions have been fitted to Voigt profiles for the vibronic pattern. Grey contributions correspond to the configuration with twisted neighbouring phenylenes and green to the planar configuration. (b) Absorption edge for $\mathrm{H}_{4}$ [6]CPP using $\mathrm{H}$-silicon carbide as anvils. (c) Absorption of spectra of [12]CPP. Grey contribution corresponds to the forbidden transition to the $S_{1}$ state produced through the HOMO-LUMO transition and blue to the transitions to the $S_{2}$ and $S_{3}$ states corresponding to the HOMO-1 -LUMO, $\mathrm{HOMO}-\mathrm{LUMO}+1$ configuration change. (d) Absorption spectra of [6]CPP. Blue contributions correspond to non-degenerate transitions to $S_{3}-S_{4}$ and to $S_{2}$, which at 0 GPa are at around 320 and $360 \mathrm{~nm}$, respectively. Grey contribution corresponds to the forbidden transition to the $\mathrm{S}_{1}$ state HOMO-LUMO transition.

Figure $8 \mathrm{c}$ shows the absorption spectra of [12]CPP at selected pressures. In addition to the redshift of the bands, the contribution from the $S_{0} \rightarrow S_{1}$ transition increases in intensity on compression. This 
agrees with the already described pressure-induced ovalisation of the cycle, which would perturb the symmetry of the excited $S_{1}$ state. Indeed, in the case of [6]CPP, whose pressure-induced deformation occurs at around $5 \mathrm{GPa}[39]$, in the visible region at around $4.7 \mathrm{GPa}$, the $\mathrm{S}_{0} \rightarrow \mathrm{S}_{1}$ contribution seems to grow in intensity (Figure $8 \mathrm{~d}$ ). However, the $\mathrm{S}_{0} \rightarrow \mathrm{S}_{1}$ intensity above $P_{\text {oval }}$ is not as high as expected for the completely allowed transition. Moreover, pressure seems to change the relative intensities of the bands for the $S_{0} \rightarrow S_{2}$ and $S_{0} \rightarrow S_{3}$ transitions. While in [12]CPP pressure favours $\pi$-conjugation [40], in [6]CPP pressure leads to a lowering of symmetry within the cycle leading to its polymerisation [39,40].

In Figure 9, the shift of the absorption bands as a function of pressure is shown for the four systems discussed here. For all the phenylene systems, the absorption redshifts with pressure as a result of a decrease in the band gap. However, the rate at which this occurs is strongly dependent on the $\pi$ configuration. Table 4 reports the coefficients of the absorption shift estimated for all the systems studied here. In systems with large $\pi$ conjugation, such as picene, the $S_{1}$ band has been observed with a redshift of $\sim 8 \mathrm{~nm} / \mathrm{GPa}$. This energy gap closure is a result of the decrease in the intramolecular distances involving $\pi-\pi$ interactions [59]. The torsional freedom of [6]LPP compared with that of picene leads to subtle changes in which the absorption bands redshift by $\sim 1 \mathrm{~nm} / \mathrm{GPa}$. In the case of $\mathrm{H}_{4}[6] \mathrm{CPP}$, there are slight changes in the slope of the absorption edge going from $\sim 2 \mathrm{~nm} / \mathrm{GPa}$ to $\sim-1 \mathrm{~nm} / \mathrm{GPa}$ at around $8 \mathrm{GPa}$, which can be associated with the pressure-induced interactions between intramolecular biphenyl as inferred from the FTIR and Raman observations. As such, [6]LPP and $\mathrm{H}_{4}[6] \mathrm{CPP}$ present analogous trends, whereas the pressure-induced interactions between cofacial phenyl units in the cycle deviates the slope (see FTIR section).
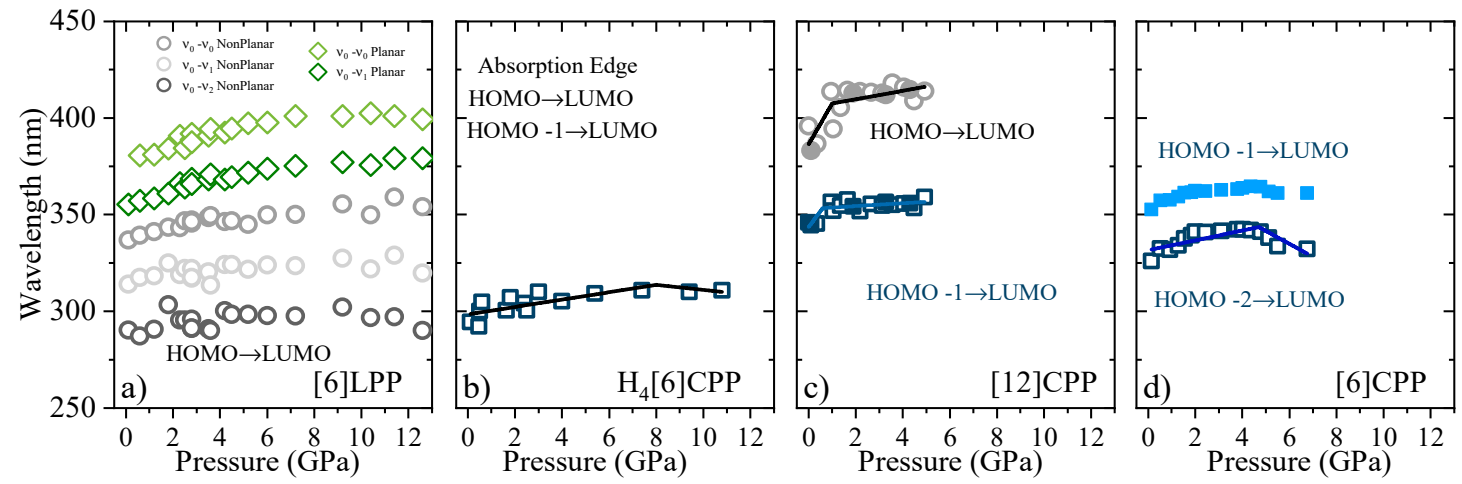

Figure 9. Pressure evolution of the absorption maxima for different crystalline compounds. (a) [6]LPP: the different vibronic transitions are reported. Grey contributions are assigned to the configuration with twisted neighbouring phenylenes and green to the planar configuration. (b) Absorption edge for $\mathrm{H}_{4}$ [6]CPP. (c) Absorption of [12]CPP. Grey contribution corresponds to the forbidden $\mathrm{S}_{0} \rightarrow \mathrm{S}_{1}$ transition, HOMO-LUMO, and blue to the $\mathrm{S}_{0} \rightarrow \mathrm{S}_{2}$ and $\mathrm{S}_{0} \rightarrow \mathrm{S}_{3}$, HOMO-1 -LUMO and HOMO-LUMO+1, respectively. (d) Absorption of [6]CPP, where blue contributions correspond to the non-degenerate $S_{0} \rightarrow S_{3}-S_{4}$, and $S_{0} \rightarrow S_{2}$. For [6]CPP, the $S_{0} \rightarrow S_{1}$ transition could not be followed as a function of pressure due to its negligible intensity.

Table 4. Experimental interceptions and pressure coefficients of the linear variation with pressure of the absorption bands before $(\mathrm{A})$ and after $(\mathrm{B})$ the ovalisation pressure $\left(P_{\text {oval }}\right)$.

\begin{tabular}{|c|c|c|c|c|c|c|c|c|c|c|}
\hline & \multicolumn{4}{|c|}{$S_{0} \rightarrow S_{1}$} & \multicolumn{3}{|c|}{$S_{0} \rightarrow S_{2}$} & \multicolumn{3}{|c|}{$S_{0} \rightarrow S_{3}-S_{4}$} \\
\hline & $\begin{array}{l}P_{\text {oval }} \\
\text { (GPa) }\end{array}$ & $\begin{array}{c}\lambda_{0} \\
(\mathrm{~nm})\end{array}$ & $\begin{array}{c}\mathrm{A} \\
(\mathrm{nm} / \mathrm{GPa})\end{array}$ & $\begin{array}{c}\text { B } \\
(\mathrm{nm} / \mathrm{GPa})\end{array}$ & $\begin{array}{c}\lambda_{0} \\
(\mathrm{~nm})\end{array}$ & $\begin{array}{c}\mathrm{A} \\
(\mathrm{nm} / \mathrm{GPa})\end{array}$ & $\begin{array}{c}\text { B } \\
(\mathrm{nm} / \mathrm{GPa})\end{array}$ & $\begin{array}{c}\lambda_{0} \\
(\mathrm{~nm})\end{array}$ & $\begin{array}{c}\mathrm{A} \\
(\mathrm{nm} / \mathrm{GPa})\end{array}$ & $\begin{array}{c}\text { B } \\
(\mathrm{nm} / \mathrm{GPa})\end{array}$ \\
\hline Picene [55] & - & 475 & $\sim 8 \pm 0.1$ & - & - & - & - & & & \\
\hline [6]LPP & - & 325 & $\sim 1 \pm 0.1$ & - & - & - & - & & & \\
\hline $\mathrm{H}_{4}[6] \mathrm{CPP}$ & 9 & 295 & $\sim 2 \pm 0.1$ & $(-1) \pm 1$ & & & - & & & \\
\hline [12]CPP & 1 & 396 & $\sim 30 \pm 0.1$ & $\sim 2 \pm 1$ & 344 & $\sim 15 \pm 2$ & $\sim 1 \pm 1$ & & & \\
\hline [6]CPP & 5 & - & - & - & 352 & $\sim 4 \pm 1$ & $\sim(-5) \pm 1$ & 326 & $\sim 8 \pm 1$ & $\sim(-9) \pm 1$ \\
\hline
\end{tabular}


Interestingly, in the case of [12]CPP, both the $S_{0} \rightarrow S_{2}$ and $S_{0} \rightarrow S_{1}$ transitions redshift with compression, presenting a change in the slope at around $1 \mathrm{GPa}, P_{\text {oval }}$, going from $\sim 15 \mathrm{~nm} / \mathrm{GPa}$ and $\sim 30 \mathrm{~nm} / \mathrm{GPa}$ to $\sim 1 \mathrm{~nm} / \mathrm{GPa}$ and $\sim 2 \mathrm{~nm} / \mathrm{GPa}$, respectively. These large slopes indicate important configurational rearrangements induced by pressure, as previous theoretical calculations estimated a band decrease of $10 \mathrm{~nm} / \mathrm{GPa}$ in the order of magnitude of the results we obtain [39,40].

In the case of [6]CPP, the $S_{0} \rightarrow S_{2}$ and the $S_{0} \rightarrow S_{3}-S_{4}$ transitions at around 5 GPa show a variation in the trend from red-shifting to blue-shifting: the $S_{0} \rightarrow S_{2}$ goes from $\sim 4 \mathrm{~nm} / \mathrm{GPa}$ to $\sim 5 \mathrm{~nm} / \mathrm{GPa}$ and the $\mathrm{S}_{0} \rightarrow \mathrm{S}_{3}-\mathrm{S}_{4}$ from $\sim 8 \mathrm{~nm} / \mathrm{GPa}$ to $\sim 9 \mathrm{~nm} / \mathrm{GPa}$. At pressures above $P_{\text {oval }} l,[6] \mathrm{CPP}$ is expected to become highly strained and deformed, with shorter intermolecular interactions [39], which explains the sudden change in the absorption trends.

\subsection{Fluorescence in Compression}

Fluorescence measurements were performed on polycrystalline samples loaded with different PTM. To avoid sample irradiation, pressure was measured through the calibrated FTIR shifts measured in the previous section; thus, the cell had to be moved between pressure points to the different setups. The dependence of the fluorescence signal intensity upon the laser power is linear or quadratic depending on whether the fluorescence follows a one-photon (OP) or two-photon (TP) absorption process. Thus, at each pressure step, the fluorescence intensity dependence was measured to determine the process type. The fluorescence spectra and pressure-trends for the three systems are shown in Figures 10 and 11. Table 5 gathers the pressure coefficients of the bands estimated for all the systems studied here.
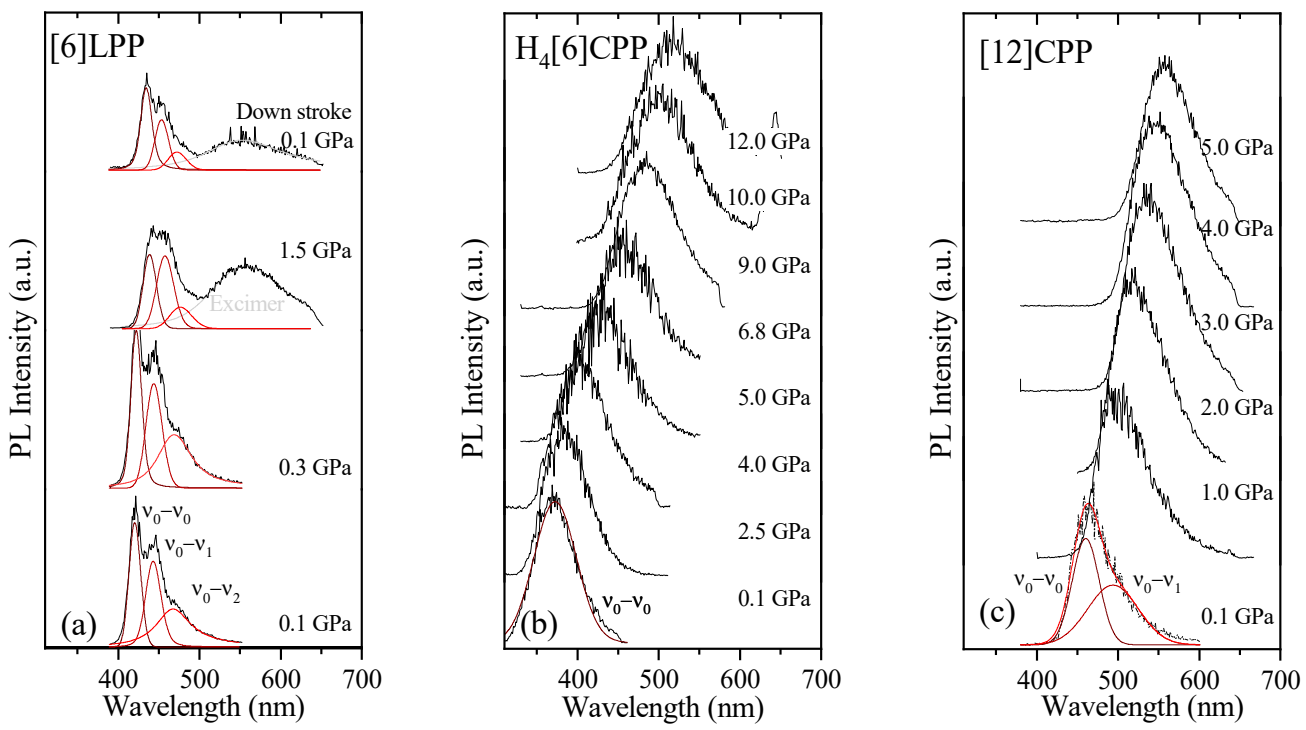

Figure 10. Fluorescence spectra at various pressures at $300 \mathrm{~K}$ for the different crystalline compounds: (a) [6]LPP; (b) $\mathrm{H}_{4}[6] \mathrm{CPP}$; and (c) [12]CPP. Spectra were fitted using Voigt profiles.

Table 5. Experimental interceptions and pressure coefficients of the linear variation with pressure of the fluorescence bands (The v0-0 has been only considered and, for $\mathrm{H}_{4}[6] \mathrm{CPP}$, two PT are indicated where the different coefficients are: before (A) and after (B) PT1, and (C) after $P T_{2}$.)

\begin{tabular}{cccccc}
\hline \multicolumn{5}{c}{$\mathbf{S}_{\mathbf{1}} \rightarrow \mathbf{S}_{\mathbf{0}}$} \\
\hline & $\boldsymbol{P T} \mathbf{( G P a )}$ & $\boldsymbol{\lambda}_{\mathbf{0}}(\mathbf{n m})$ & $\mathbf{A ~ ( n m / G P a )}$ & $\mathbf{B}(\mathbf{n m} / \mathbf{G P a})$ & $\mathbf{C}(\mathbf{n m} / \mathbf{G P a})$ \\
\hline Picene [55] & & 475 & $\sim 6.0$ & - \\
[6]LPP & $>1$ & 440 & $\sim 2 \pm 0.2$ & - & - \\
$\mathrm{H}_{4}$ [6]CPP & $4,9-10$ & 375 & $\sim 5 \pm 1$ & $\sim 20 \pm 2$ & $\sim 8 \pm 1$ \\
[12]CPP & 1 & 462 & $\sim 50 \pm 4$ & $\sim 10 \pm 2$ & - \\
\hline
\end{tabular}


TP fluorescence spectra of [6]LPP were measured using $740 \mathrm{~nm}$ as an excitation line. The fluorescence spectra of [6]LPP are characterised by the $S_{1} \rightarrow S_{0}$ emission, which shows a well-defined vibronic pattern. [6]LPP initially was loaded without a PTM; however, during the high-pressure fluorescence experiments of [6]LPP, the formation of an excimer at pressures below 2 GPa was characterised by a fluorescence band at around $550 \mathrm{~nm}$. The excimer formation is a very interesting result because it has strong intensity at very low pressure. This behaviour is different to benzene, which showed a sudden intensity exchange between the monomer and excimer transitions at around 6.1 GPa [61]. Here, formation of the excimer is likely due to the presence of defects among the crystal grains and not the reactivity trigger as IR showed much higher pressures are required. Consequently, it was necessary to work with an inert PTM to avoid the formation of such defects. In these conditions, the excimer was still present. On the other hand, as seen in Figure 10a, the different vibronic transitions are observed as they all redshift with increasing pressure. Figure 11a shows the shift of the three vibronic contributions as a function of pressure. Our results are in excellent agreement with those of Guha et al. [59]. All the data reported show a significant band gap decrease with increasing pressure, with an average linear pressure coefficient $2 \mathrm{~nm} / \mathrm{GPa}$ calculated above planarisation (ca. $1 \mathrm{GPa}$ ), which is in agreement with the absorption measurements.
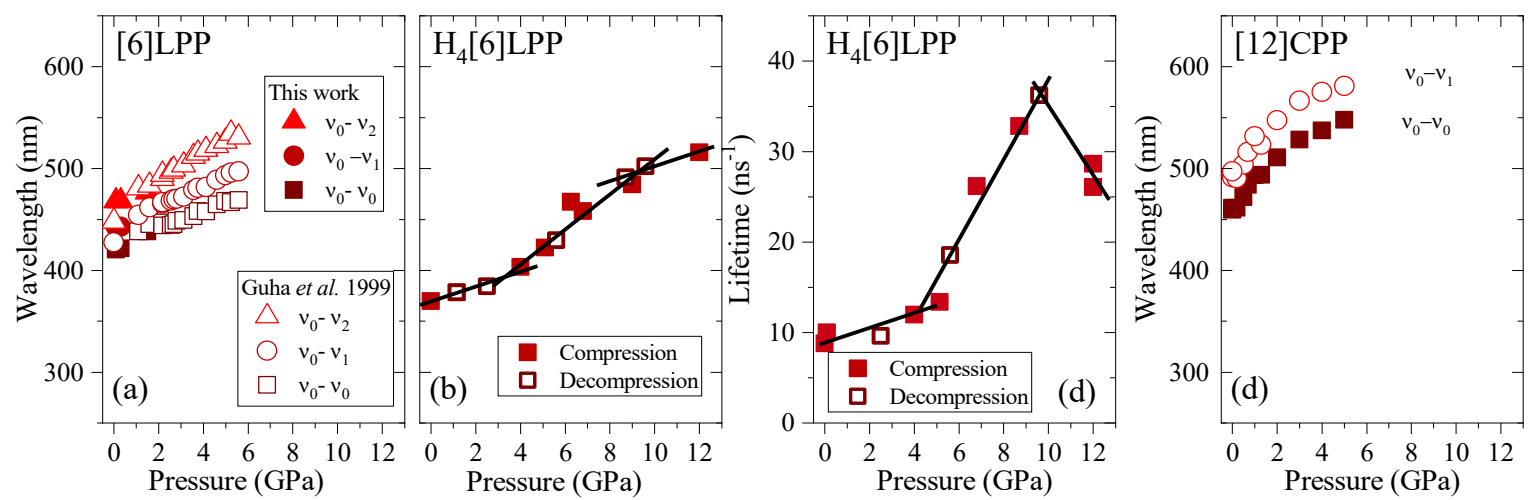

Figure 11. Emission data represented as a function of pressure for the different crystalline compounds. (a) Transition energies of [6]LPP: empty symbols correspond to the experimental results from Guha et al. [60]. (b) Transition energy (0-0) of $\mathrm{H}_{4}$ [6]CPP. (c) Fluorescence lifetime of $\mathrm{H}_{4}$ [6]CPP. (d) Transition energies of [12]CPP.

In $\mathrm{H}_{4}[6] \mathrm{CPP}$, fluorescence spectra were measured using different excitation wavelengths between 540 and $660 \mathrm{~nm}$. The spectra at selected pressures are presented in Figure 10b. In contrast to [6]LPP, $\mathrm{H}_{4}$ [6]LPP fluorescence is a broad single band, which is assigned as a $0-0$ vibronic transition. The TP excitation profile was also measured at selected pressures, detecting fluorescence around its maximum. As in the absorbance experiments, $\mathrm{H}_{4}[6] \mathrm{CPP}$ shows a significant redshift in compression at about $150 \mathrm{~nm}$ in the $12 \mathrm{GPa}$ range (Figure 11b). Moreover, the lifetime of the $\mathrm{S}_{1} \rightarrow \mathrm{S}_{0}$ emission was measured as a function of pressure and a striking increase in lifetime is observed, going from $9 \mathrm{~ns}$ at low pressure to a maximum of $38 \mathrm{~ns}$ at $9 \mathrm{GPa}$ as shown in Figure 11c. Measurements in compression and decompression were conducted to ensure reversibility of the process. Interestingly, unlike in [6]LPP, three regimes are observed: 0-4 GPa with a coefficient of $\sim 5 \mathrm{~nm} / \mathrm{GPa}$ and lifetime increase of $\sim 0.8 \mathrm{~ns} / \mathrm{GPa}$; $4-9$ GPa with a redshift coefficient of $\sim 20 \mathrm{~nm} / \mathrm{GPa}$ and lifetime increase of $\sim 5 \mathrm{~ns} / \mathrm{GPa}$; and a third regime up to $12 \mathrm{GPa}$ in which the coefficient is smaller with $\sim 8 \mathrm{~nm} / \mathrm{GPa}$ and lifetime decrease from a rate of $-3 \mathrm{~ns} / \mathrm{GPa}$. This change in rate coincides approximately with the maximum pressure for which $\mathrm{X}$-ray data could be collected. The diffraction data at $4.59 \mathrm{GPa}$ are much weaker than at lower pressures, which may point to gradual transformations. These results in the change in the optical properties with pressure confirm that $\mathrm{H}_{4}[6] \mathrm{CPP}$ undergoes intramolecular changes involving $\pi-\pi$ interactions. This can be interpreted as the increase in the dipole moment of the excited state with stronger $\pi-\pi$ intramolecular interactions causing a decrease in the transition energies [62]. At pressures above $9 \mathrm{GPa}$, further compression leads 
to stronger intramolecular connections that do not seem to be so energetically favoured as the energy gap does not decrease so steeply, whereas compression up to 12 GPa seems to lead to a product without covalent bond formation as the process is fully reversible.

In Figure 10c, the TP fluorescence spectra of [12]CPP at selected pressures are presented. These were measured with an excitation line of $760 \mathrm{~nm}$. The asymmetry in the fluorescence profile indicates that the spectra are formed by at least two different contributions as previously described [35,63]. We have fitted the spectrum to two contributions where the energy spacing between these peaks is approximately $40 \mathrm{~nm}$, corresponding to approximately $1450 \mathrm{~cm}^{-1}$ and matching the phenylene stretching vibration [64]. [12]CPP fluorescence shows a redshift of the same order of magnitude as in the absorption measurements (Figure 11d). The average shift of the vibronic modes gives a redshift of $50 \mathrm{~nm} / \mathrm{GPa}$ up to $1 \mathrm{GPa}$ and of $10 \mathrm{~nm} / \mathrm{GPa}$ above $1 \mathrm{GPa}$. These results are in line with the compression of a low-pressure rigid phase in which pressure would favour the cyclic conjugation $[40,49,65]$.

[6]CPP fluorescence was measured with OP and TP excitations, and pressures below and above ovalisation pressure. However, significant fluorescence could not be detected for any configuration. This lack of results indicates that the deformation of the cycle does not allow the $S_{0} \rightarrow S_{1}$ transition and confirms the fact that the absorbance observed in the bigger cycles at room pressure cannot be related with a Jahn-Teller effect [37].

\section{Discussion}

In this section, the results obtained through different diagnostics are presented together. The discussion will be presented individually for each of the systems by describing the main spectral changes observed during compression and how these are interpreted. Table 6 summarises the main points.

[6]LPPs. Around the 1-2 GPa range, these conduct planarisation towards their $\mathrm{D}_{2 \mathrm{~h}}$ symmetry. At the same time, compression induces continuous reduction of the lattice parameters through the intermolecular distance decrease [16,17]. Absorption and fluorescence data of up to 12 and $6 \mathrm{GPa}$, respectively, indicate that pressure induces a band gap reduction. However, this reduction is not as large as expected if $\pi-\pi$ interactions were strongly favoured. This is related to the fact that [6]LPP molecules are arranged in a herringbone structure within which the neighbouring molecules are not coplanar and, consequently, higher pressures than $12 \mathrm{GPa}$ are required to facilitate their interactions. Fourier Transformation Infrared (FTIR) spectroscopy demonstrates that pressures of 23 GPa lead to the formation of a system characterised by an intense C-H stretching band typical of saturated systems. Consequently, we can consider that pressure induces shortening between intermolecular distances that at around $23 \mathrm{GPa}$ leads to the formation of intermolecular linkages, generating a 3D $\pi$-bonded structure.

$\mathrm{H}_{4}$ [6]CPP. Our XRD experiments demonstrate that compression leads to an important decrease within the intramolecular distances up to $4.59 \mathrm{GPa}$. Therefore, it could be expected that further compression would facilitate the formation of intramolecular interactions by shortening the biphenyl intramolecular distances. In this sense, compressions at 12 and $10 \mathrm{GPa}$ are shown to be fully reversible according to Raman and fluorescence experiments. However, compression above 16 GPa causes the irreversible growth of $\mathrm{n}$ IR band in the region of $\mathrm{C}-\mathrm{H}$ stretching of saturated carbon atoms, which can be interpreted by the formation of permanent intramolecular bonds. On the other hand, $\mathrm{H}_{4}$ [6]CPP optical properties present a unique response to pressure, with a sharp decrease in the band gap and increase in the lifetime. The lifetimes reach values of $38 \mathrm{~ns}$, with emission in the green region, making these molecules uniquely suitable for use in optoelectronic devices modulated by strain. We believe this behaviour is due to the flexibility that the cyclohexadiene connecting rings provide to the cycle; that is, they can bend to shortening between the intramolecular biphenyl units favouring the $\pi-\pi$ interaction while the double bonds of the cyclohexadienes favour conjugation within the molecule as well.

When the phenyl configuration is cyclic, the observed results depend on size. As in the non-conjugated cycle paraphenylene, no irreversibility in the vibrational or optical properties for [12]CPP is seen when compressed up to $12 \mathrm{GPa}$. It is known that cyclic conjugation decreases with the 
increasing size of the ring and also that compression induced a change into the circular section towards oval, which occurs at around 1 GPa for [12]CPP [40]. The absorption and fluorescence results presented here demonstrate that compression up to $1 \mathrm{GPa}$ leads to a decrease in the HOMO-LUMO gap of about $0.26 \mathrm{eV}$. This value is within the calculated difference between a relaxed [12]CPP with alternated torsions and either a cycle with no torsional angles between neighbouring phenyl units or between [12]CPP and [8]CPP with larger cyclic conjugation [49]. Therefore, when [12]CPP is compressed in the rigid circular regime, the cyclic conjugation is favoured. However, at pressures above $1 \mathrm{GPa}$, compression leads to deformation of the cycle and adoption of an oval configuration.

Table 6. Summary of the main results obtained from the different techniques. "—" indicates either there are not data collected or no significant changes are observed through the marked diagnostic.

\begin{tabular}{|c|c|c|c|c|c|}
\hline System & Comments & FTIR & Raman & Absorption & Fluorescence \\
\hline \multirow{3}{*}{ [6]LPP } & $\begin{array}{l}1 \text { to } 2 \mathrm{GPa}: \\
\text { planarisation }\end{array}$ & $\begin{array}{l}\text { Spectral changes, } \\
\text { new bands [66] }\end{array}$ & $\begin{array}{l}\text { Change in slope of } \\
\text { the } G_{A 1 g} \text { mode }\end{array}$ & $\begin{array}{l}\text { Change in the } \\
\text { absorption profile }\end{array}$ & - \\
\hline & $1-23 \mathrm{GPa}$ & $\begin{array}{l}\text { Steep upshift C-H } \\
\text { stretching modes }\end{array}$ & 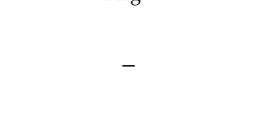 & $\begin{array}{c}\text { Steep upshift, } \\
\text { measurements } \\
\text { conducted up to } \\
12 \mathrm{GPa}\end{array}$ & $\begin{array}{c}\text { Steep upshift } \\
\text { measurements } \\
\text { conducted up to } \\
12 \mathrm{GPa}\end{array}$ \\
\hline & $\begin{array}{c}\text { P > } 23 \text { GPa: } \\
\text { polymerisation }\end{array}$ & $\begin{array}{l}\text { C-H stretching from } \\
\mathrm{sp}^{3} \text { carbon }\end{array}$ & - & 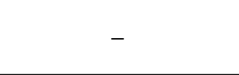 & - \\
\hline \multirow[t]{3}{*}{$\mathrm{H}_{4}[6] \mathrm{CPP}$} & $\begin{array}{c}\text { 1-4.59 GPa, } \\
\text { intramolecular } \\
\text { distance decrease, } \\
\text { XRD }\end{array}$ & \multicolumn{3}{|c|}{ No significant changes } & $\begin{array}{c}\text { Change in slope at } \\
5 \mathrm{GPa} \text { of the } \\
\text { emission bands }\end{array}$ \\
\hline & $\begin{array}{l}4.6 \text { to } 10 \mathrm{GPa}: \\
\text { pressure induces } \pi-\pi \\
\text { interactions }\end{array}$ & $\begin{array}{l}\mathrm{C}-\mathrm{H} \text { stretching from } \\
\mathrm{sp}^{3} \text { carbon decrease } \\
\text { in intensity }\end{array}$ & $\begin{array}{l}\text { Change in slope of } \\
\text { the } G_{A 1 g} \text { mode }\end{array}$ & $\begin{array}{l}\text { Change in slope at } \\
10 \mathrm{GPa} \text { of the } \\
\text { absorption bands }\end{array}$ & $\begin{array}{l}\text { Change in slope } \\
10 \mathrm{GPa} \text { of the } \\
\text { emission bands }\end{array}$ \\
\hline & $\begin{array}{l}\mathrm{P}> \\
\text { 16 GPa:polymerisation }\end{array}$ & $\begin{array}{l}\text { C-H stretching from } \\
\mathrm{sp}^{3} \text { carbon }\end{array}$ & - & - & - \\
\hline \multirow[t]{2}{*}[12]{$\mathrm{CPP}$} & $\begin{array}{c}\text { 0.6 GPa: } \\
\text { deformation of the } \\
\text { cycle, ovalisation: } \\
\text { favoured } \\
\text { intramolecular } \\
\text { conjugation }\end{array}$ & - & $\begin{array}{l}\text { Change in slope of } \\
\text { the } G_{A 1 g} \text { mode }\end{array}$ & $\begin{array}{l}\text { Change in slope of } \\
\text { absorption bands; } \\
\text { HOMO-LUMO } \\
\text { absorption becomes } \\
\text { more intense }\end{array}$ & $\begin{array}{l}\text { Change in slope of } \\
\text { emission band }\end{array}$ \\
\hline & Up to $10 \mathrm{GPa}$ & \multicolumn{4}{|c|}{ No significant changes } \\
\hline [6]CPP & $\begin{array}{l}5 \text { GPa: Deformation } \\
\text { of the cycle and } \\
\text { intermolecular } \\
\text { polymerisation }\end{array}$ & $\begin{array}{l}\mathrm{C}-\mathrm{H} \text { stretching from } \\
\mathrm{sp}^{3} \text { carbon appears } \\
\text { in decompression }\end{array}$ & $\begin{array}{l}\text { Change in slope of } \\
\text { the } \mathrm{G}_{\mathrm{A} 1 \mathrm{~g}} \text { mode and } \\
\text { irreversibility on } \\
\text { decompression }\end{array}$ & $\begin{array}{l}\text { Change in slope of } \\
\text { absorption bands; } \\
\text { HOMO-LUMO } \\
\text { absorption becomes } \\
\text { more intense }\end{array}$ & None observed \\
\hline
\end{tabular}

In the case of [6]CPP, the one with the largest cyclic conjugation and the smallest band gap, its large strain hinders the modulation of these properties. As discussed, pressure induces the formation and asymmetrisation of the cycle, leading to intermolecular interactions that for above 5 GPa have been detected to be irreversible. This work intended to explore the possibility of perturbing the selection rules to activate the $\mathrm{S}_{0} \rightarrow \mathrm{S}_{1}$ absorption or emission through the deformation of the cycle and perturbation of the selection rules. However, no $S_{0} \rightarrow S_{1}$ absorption or emission was detected either through OP or TP excitations.

This work highlights the fact that different phenyl configurations lead to different physical properties of the materials. Curvature, strain and electronic $\pi$-conjugation are the main characteristics of [n]CPPs. [6]LPP exhibits different properties to [6]CPP; i.e., the former shows linear $\pi$-conjugation being enhanced by pressure and the latter shows that cyclic conjugation is perturbed by molecular deformations. Although large [n]CPPs are thought to have features close to those of long [n]LPPs, this work demonstrates some important differences between the two systems. The best example is provided by evaluation of the fluorescence of [6]LPP and [12]CPP, as the latter is more affected by compression as it assists the cyclic conjugation that causes an important reduction of its band gap, absorption and emission coefficients more than three times those in[6]LPP. 
$\mathrm{H}_{4}[6] \mathrm{CPP}$ was studied with the intention to provide a link between linear and cyclic $\pi$-conjugation. Interestingly, here we find that this non-conjugated cyclic system presents attractive optical properties of its own. The closure between biphenyl units and the flexibility of the cyclohexadiene units configures it with exclusive $\pi$-conjugation as shown by its characteristic photoluminescence. The $\mathrm{H}_{4}[6] \mathrm{CPP}$ compression leads to intramolecular $\pi$-interactions, resulting in an important decrease of the band gap. Therefore, this non-conjugated cycle takes the advantages of the intramolecular deformability of the CPPs and the linear conjugation provided by the biphenyl units, but without the added strain provided by the bending of the phenyl units in the CPPs. Consequently, $\mathrm{H}_{4}[6] \mathrm{CPP}$ configures a great link between linear and cyclic paraphenylenes.

\section{Materials and Methods}

[6]LPP was purchased from TCI. [12]CPP was provided by Yamago et al. and synthesised using a synthetic strategy through multinuclear arylplatinum complexes [29]. [6]CPP and $\mathrm{H}_{4}$ [6]CPP were provided by Jasti et al. and synthesised through Suzuki-Miyaural cross-coupling/macrocyclisation to generate macrocycles and their consecutive reduction routes [54].

\subsection{X-ray Crystallography}

Single-crystal diffraction data were collected at ambient pressure and room temperature using a crystal of dimensions $0.6 \times 0.3 \times 0.1 \mathrm{~mm}^{3}$ on a Rigaku-Oxford Diffraction SuperNova 4-circle goniometer diffractometer (Wroclaw, Poland) using $\mathrm{Cu}-\mathrm{K} \alpha$ radiation $(\lambda=1.54184 \AA$ ).

Diffraction data at high pressure were collected using a crystal of dimensions $0.3 \times 0.2 \times 0.1 \mathrm{~mm}^{3}$, which was loaded together with a ruby chip into a Merrill-Bassett-type diamond anvil cell (DAC) consisting of $600 \mu \mathrm{m}$ cut diamonds and a tungsten gasket mounted on tungsten-carbide backing seats. The cell was cryo-loaded in argon as a hydrostatic medium. The diffraction experiments were performed at room temperature using silicon(111) monochromated synchrotron radiation $(\lambda=0.4859 \AA)$ on beamline I19 at the Diamond Light Source, Didcot, UK. Data were collected at 1.43, 1.96, 3.33 and $4.59 \mathrm{GPa}$ and, in all cases, the pressure was measured using the ruby fluorescence method [67].

\subsection{Structure Analysis}

All data were processed and integrated with the program CrysaAlisPro [68]. The cell parameters were obtained using Xia2 [69-73].

The multi-scan method was used to treat systematic errors. Structures were solved using direct methods (SHELEXT) [74] and refined by full-matrix least squares of $\mathrm{F}^{2}$ (SHELXL) [74] using the Olex2 graphical user interface [75]. Structures were visualised with MERCURY [76].

\subsection{Interaction Energies Calculation}

Molecular electron densities and lattice energies were calculated in CrystalExplorer version 17.5 (University of Western Australia, Perth, Australia) by the embodied TONTO software. The calculations were performed at the B3LYP level with the $6-13 G^{* *}(\mathrm{~d}, \mathrm{p})$ basis set, using molecular geometries from the crystal structures at ambient pressure and $4.59 \mathrm{GPa}$ of $\mathrm{H}_{4}[6] \mathrm{CPP}$. The $\mathrm{C}-\mathrm{H}$ bond lengths were normalised to standard neutron diffraction values [12,77].

\subsection{FTIR}

Infrared spectra were measured in the mid-IR region of $600-5000 \mathrm{~cm}^{-1}$ with a spectral resolution of $1 \mathrm{~cm}^{-1}$ using a Bruker IFS-120HR FTIR spectrometer (Bruker Corporation, Billerica, MA, USA) modified to allow in situ measurements in the DAC [78]. The FTIR spectra were measured just after loading a membrane diamond anvil cell (MDAC) to check the initial sample purity during compression and decompression. Type II diamond anvils were used with diameter culet of $300 \mu \mathrm{m}$, using Inconel as gasket material with a final thickness of $40 \mu \mathrm{m}$ thick with $150 \mu \mathrm{m}$ hole. Samples were loaded together 
with a solid solution of $\mathrm{KBr}$ and $\mathrm{NaNO}_{2}$ (99:1). Pressure was monitored by the fluorescence of a ruby chip placed together with the sample in the chamber.

\subsection{Raman Spectroscopy}

Raman measurements at ambient and approximately hydrostatic high-pressure conditions were conducted with a Senterra dispersive Raman spectrometer from Bruker (Bruker Corporation, Billerica, MA, USA) with a $785 \mathrm{~nm}$ excitation wavelength and standard spectral resolution of $3 \mathrm{~cm}^{-1}$ [79]. Pressure studies were conducted in a screw-driven sapphire anvil cell (SAC) with anvils of a diameter culet of $380 \mu \mathrm{m}$. Pressures up to $12 \mathrm{GPa}$ were reached, although for each [n]CPP, the maximum pressure achieved was slightly different. No PTM was used and diamond chips were employed as a pressure calibrant [80].

\subsection{Near-UV-Visible Absorption}

Near-UV-visible spectra were measured with a homemade spectrometer designed for UV-vis absorption measurements in the anvil cell. The main incorporated components are a CCD - model S9971- 1006UV by Hamamatsu (Photonics K.K., Hamamatsu, Japan), and monochromator - model 77250 by Newport (Newport Corporation, Irvine, CA, USA). The light source was a xenon lamp (Hamamatsu L10725) attenuated by UV-fused silica neutral-density filters with varying optical densities and filtered by a short-pass filter with a cut-off wavelength at $450 \mathrm{~nm}$ to reject light out of the desired spectral range. The light was focused onto the sample and collected by a couple of $\mathrm{Al}$-coated $90^{\circ}$ off-axis parabolic mirrors (with a reflected focal length of $50.8 \mathrm{~mm}$ ). Then, the light was focused by Al-coated $90^{\circ}$ off-axis parabolic mirrors into a $1 / 8 \mathrm{~m}$ monochromator (Newport 77250), with an $\mathrm{F} /$ number $=$ F/3.7. The light was dispersed by a ruled grating (Newport 77304) with 600 lines/mm blazed at $200 \mathrm{~nm}$ and collected on a CCD (Hamamatsu S9971-1006UV). The resulting spectral resolution was $3 \mathrm{~nm}$. Pressure-dependent measurements were done using MDAC with ultra-low fluorescence diamonds with diameter culet of $300 \mu \mathrm{m}$, using Inconel as gasket, being this of $40 \mu \mathrm{m}$ thick with $150 \mu \mathrm{m}$ hole. $\mathrm{H} 4[6] \mathrm{CPP}$ pressure-dependent measurements were done using a screw-driven $\mathrm{H}$-silicon carbide anvil cell, with $400 \mu \mathrm{m}$ culets, Inconel as gasket being this of $30 \mu \mathrm{m}$ thick with $100 \mu \mathrm{m}$ hole. No PTM was used and pressure was monitored by the fluorescence of a ruby chip placed together with the sample in the chamber. Absorption of the anvils with the sample chamber loaded with water was used as reference.

\subsection{Fluorescence}

The fluorescence measurements were performed on polycrystalline samples using a picosecond tunable source and to detect the fluorescence in a backscattering geometry in a setup detailed in Ref. [60]. In the present work, the beam was focused with a $100 \mathrm{~mm}$ focal length achromatic doublet to obtain a beam-waist diameter of comparable dimensions with the gasket aperture and a depth of focus longer than the sample thickness. A parabolic $\mathrm{Al}$ mirror was used to collect fluorescence, which was focused on a monochromator - model Cornerstone 74100 by Oriel Instruments (now part of Newport corporation, Irvine, CA, USA) and measured by a cooled Hamamatsu R943-02 photomultiplier (Hamamatsu Photonics K.K., Hamamatsu, Japan). Pressure-dependent measurements were done using MDAC provided with ultra-low fluorescence diamonds with diameter culet of $300 \mu \mathrm{m}$, using Inconel as gasket, being this of $40 \mu \mathrm{m}$ thick with $150 \mu \mathrm{m}$ hole. The sample was loaded with no PTM unless otherwise specified. Pressure was determined by measuring the FTIR spectrum, using the calibrated frequency shift of the infrared absorption bands of the own paraphenylene. Fluorescence spectra were measured with a resolution of $\sim 1 \mathrm{~nm}$. The sampling of the excitation profiles was set to $1 \mathrm{~nm}$.

\section{Conclusions}

We have demonstrated that phenyl conjugation is a powerful element whose properties can be exploited through the synthesis of attractive structures with different configurations and through 
mechanical compression. The understanding of this novel and interesting concept provides us with the basic tools needed to synthesise tailored molecular materials with the desired properties.

In this work, we show how different arrangements of phenyl units lead to different pressure modulation of their properties. In [n]LPPs, compression favours linear conjugation through molecular planarisation and intramolecular interactions. In the case of non-conjugated cyclic $\mathrm{H}_{4}[6] \mathrm{CPP}$, spectroscopic results show how, through compression, conjugation within the molecule is favoured, with the resultant band gap reduction. This may be the most remarkable finding as it opens a broad spectrum of possibilities to use this molecular arrangement in the field of optoelectronic applications. Finally, in the case of strained [n]CPPs, compression of [12]CPP within the low-pressure configuration decreases its band gap; however, once it deforms, the band gap closure narrows and no significant intramolecular rearrangements are observed. In [6]CPP, with higher molecular strain, higher pressures are required to deform the cycle and break the symmetry selection rules; however, there is a tendency of a band gap increase. Such an increase is a consequence of the loss of cyclic conjugation, which is responsible for the low band gap in pristine [6]CPP.

Supplementary Materials: The following are available online, Figures S1-S10. Table S1.

Author Contributions: M.P.A. designed the project, did the data analysis and project writing. M.P.A., S.F., N.F., M.C., R.B., V.G.B. and M.T. conducted the experiments. G.N. and S.P. did the XRD experiments and analysis of $\mathrm{H}_{4}[6]$ CPP. All the authors contributed to the revision and editing of the manuscript.

Funding: This research was funded by European Laboratory for Non-Linear Spectroscopy, grant number LENS002098 and LENS002275.

Acknowledgments: We thank S. Yamago et al. and R. Jasti for providing some samples. We thank J. Binns for fruitful discussions and R. Turnbull for his help in argon loading. Financial support from MINECO, Government of Spain is acknowledged (project reference FEDER CTQ2015-69391-P). This work has been supported also by MINECO through the projects CSD2007-00045, CTQ2015-67755-C2-1-R and CTQ2013-48252-P. MPA is grateful to the European Laboratory for Non-Linear Spectroscopy for funding the project through the proposals LENS002098 and LENS002275. M.P.-A. would like to acknowledge the support of the European Research Council (ERC) Grant 'Hecate' Reference No. 695527 held by Graeme Ackland.

Conflicts of Interest: The authors declare no conflicts of interest.

\section{References}

1. Chiang, C.K.; Fincher, C.R., Jr.; Park, Y.W.; Heeger, A.J.; Shirakawa, H.; Louis, E.J.; Gau, S.C.; MacDiarmid, A.G. Electrical conductivity in doped polyacetylene. Phys. Rev. Lett. 1977, 39, 1098-1101. [CrossRef]

2. Nicol, M.; Yin, G.Z. Organic chemistry at high pressure: Can unsaturated bonds survive 10 GPa? J. Phys. Colloq. 1984, 45, C8-163-C8-172. [CrossRef]

3. Aguiar, A.L.; Capaz, R.B.; Filho, A.G.S.; San-Miguel, A. Structural and phonon properties of bundled single-and double-wall carbon nanotubes under pressure. J. Phys. Chem. C 2012, 116, 22637-22655. [CrossRef]

4. Imtani, A.N.; Jindal, V.K. Structure of chiral single-walled carbon nanotubes under hydrostatic pressure. Comput. Mater. Sci. 2009, 46, 297-302. [CrossRef]

5. Fitzgibbons, C.; Guthrie, M.; Xu, E.; Crespi, V.H.S.; Davidowski, K.; Cody, G.D.; Alem, N.; Badding, J.V. Benzene-derived carbon nanothreads. Nat. Mater. 2015, 14, 43. [CrossRef]

6. Hanfland, M.; Brillante, A.; Syassen, K.; Stamm, M.; Fink, J. Polyparaphenylene under pressure: Optical absorption and vibrational modes. J. Chem. Phys. 1989, 90, 1930-1934. [CrossRef]

7. Alvarez, M.P.; Burrezo, P.M.; Kertesz, M.; Iwamoto, T.; Yamago, S.; Xia, J.; Jasti, R.; Navarrete, J.T.L.; Taravillo, M.; Baonza, V.G.; et al. Properties of Sizeable [ $n$ ] Cycloparaphenylenes as Molecular Models of Single-Wall Carbon Nanotubes Elucidated by Raman Spectroscopy: Structural and Electron-Transfer Responses under Mechanical Stress. Ang. Chem. Int. Ed. 2014, 53, 7033-7037.

8. Cuff, L.; Kertesz, M. Ab initio oligomer approach to vibrational spectra of polymers: Comparison of helical and planar poly (p-phenylene). Macromolecules 1994, 27, 762-770. [CrossRef]

9. Zerbi, G.; Chierichetti, B.; Inganas, O. Vibrational spectra of oligothiophenes as model of polythiophenes. J. Chem. Phys. 1991, 94, 4637-4645. [CrossRef]

10. Furumoto, H.W.; Ceccon, H.L. Ultraviolet organic liquid lasers. J. Quant. Elec. 1970, 6, 262. [CrossRef] 
11. Tiekink, E.R.; Zukerman-Schpector, J. (Eds.) The Importance of Pi-Interactions in Crystal Engineering: Frontiers in Crystal Engineering; John Wiley and Sons: Chichester, UK, 2012.

12. Lukes, V.; Justina, A.; Aquino, A.; Lischka, H.; Kauffmann, H.F. Dependence of optical properties of oligo-para-phenylenes on torsional modes and chain length. J. Phys. Chem. B 2007, 111, 7954-7962. [CrossRef]

13. Guha, S.; Graupner, W.; Resel, R.; Chandrasekhar, M.; Chandrasekhar, H.R.; Glaser, R.; Leising, G. Planarity of para hexaphenyl. Phys. Rev. Lett. 1999, 82, 3625-3628. [CrossRef]

14. Zhuravlev, K.K.; McCluskey, M.D. Excitation of crystalline all-trans retinal under pressure. J. Chem. Phys. 2001, 114, 5465-5467. [CrossRef]

15. Zhuravlev, K.K.; McCluskey, M.D. Conformation of p-terphenyl under hydrostatic pressure. J. Chem. Phys. 2004, 120, 1841-1845. [CrossRef] [PubMed]

16. Guha, S.; Graupner, W.; Resel, R.; Chandrasekhar, M.; Chandrasekhar, H.R.; Glaser, R.; Leising, G. Tuning intermolecular interactions: A study of the structural and vibrational properties of p-hexaphenyl under pressure. J. Phys. Chem. A 2001, 105, 6203-6211. [CrossRef]

17. Heimel, G.; Puschnig, P.; Oehzelt, M.; Hummer, K.; Koppelhuber-Bitschnau, B.; Porsch, F.; Ambrosch-Draxl, C.; Resel, R. Chain-length-dependent intermolecular packing in polyphenylenes: A high pressure study. J. Phys. Condens. Matter 2003, 15, 3375. [CrossRef]

18. Li, P.; Sisto, T.J.; Darzi, E.R.; Jasti, R. The effects of cyclic conjugation and bending on the optoelectronic properties of paraphenylenes. Org. Lett. 2014, 16, 182-185. [CrossRef]

19. Tahara, K.; Tobe, Y. Molecular loops and belts. Chem. Rev. 2006, 106, 5274-5290. [CrossRef]

20. Kayahara, E.; Kumar Patel, V.; Yamago, S. Synthesis and characterization of [5] cycloparaphenylene. J. Am. Chem. Soc. 2014, 136, 2284-2287. [CrossRef]

21. Darzi, E.R.; Jasti, R. The dynamic, size-dependent properties of [5]-[12] cycloparaphenylenes. Chem. Soc. Rev. 2015, 44, 6401-6410. [CrossRef]

22. Iwamoto, T.; Watanabe, Y.; Sadahiro, T.; Haino, T.; Yamago, S. Size-selective encapsulation of C60 by [10] cycloparaphenylene: Formation of the shortest fullerene-peapod. Angew. Chem. Int. Ed. 2011, 50, 8342-8344. [CrossRef]

23. Bunz, U.H.F.; Menning, S.; Martín, N. para-Connected cyclophenylenes and hemispherical polyarenes: Building blocks for single-walled carbon nanotubes? Angew. Chem. Int. Ed. 2012, 51, 7094-7101. [CrossRef]

24. Schrettl, S.; Frauenrath, H. Elements for a rational polymer approach towards carbon nanostructures. Angew. Chem. Int. Ed. 2012, 51, 6569-6571. [CrossRef]

25. Iwamoto, T.; Watanabe, Y.; Takaya, H.; Haino, T.; Yasuda, N.; Yamago, S. Size-and Orientation-Selective Encapsulation of C70 by Cycloparaphenylenes. Chem. Eur. J. 2013, 19, 14061-14068. [CrossRef]

26. Gonzalez-Veloso, I.; Cabaleiro-Lago, E.M.; Rodriguez-Otero, J. Fullerene size controls the selective complexation of [11] CPP with pristine and endohedral fullerenes. J. Phys. Chem. Chem. Phys. 2018, 20, 11347-11358. [CrossRef]

27. Rio, J.; Beeck, S.; Rotas, G.; Ahles, S.; Jacquemin, D.; Tagmatarchis, N.; Ewels, C.; Wegner, H.A. Electronic Communication between two [10] cycloparaphenylenes and Bis (azafullerene)(C59N) 2 Induced by Cooperative Complexation. Angew. Chem. 2018, 57, 6930-6934. [CrossRef]

28. Bachrach, S.M.; Stück, D. DFT study of cycloparaphenylenes and heteroatom-substituted nanohoops. J. Org. Chem. 2010, 75, 6595-6604. [CrossRef]

29. Iwamoto, T.; Watanabe, Y.; Sakamoto, Y.; Suzuki, T.; Yamago, S. Selective and random syntheses of [n] cycloparaphenylenes $(n=8-13)$ and size dependence of their electronic properties. J. Am. Chem. Soc. 2011, 133, 8354-8361. [CrossRef]

30. Segawa, Y.; Omachi, H.; Itami, K. Theoretical studies on the structures and strain energies of cycloparaphenylenes. Org. Lett. 2010, 12, 2262-2265. [CrossRef]

31. Segawa, Y.; Fukazawa, A.; Matsuura, S.; Omachi, H.; Yamaguchi, S.; Irle, S.; Itami, K. Combined experimental and theoretical studies on the photophysical properties of cycloparaphenylenes. Org. Biomol. Chem. 2012, 10, 5979-5984. [CrossRef]

32. Nizhegorodov, N.I.; Downey, S.W.; Danailov, M.B. Systematic investigation of absorption, fluorescence and laser properties of some p-and m-oligophenylenes. Spectrochim. Acta A 2000, 56, 783-795. [CrossRef]

33. Fujitsuka, M.; Kayahara, E.; Lu, C.; Yamago, S.; Majima, T. Significant structural relaxations of excited [n] cycloparaphenylene dications $(\mathrm{n}=5-9)$. Phys. Chem. Chem. Phys. 2018, 20, 29207-29211. [CrossRef] 
34. Lin, J.B.; Darci, E.R.; Jasti, R.; Yavuz, I.; Houk, K.N. Solid-State Order and Charge Mobility in [5]- to [12] Cycloparaphenylenes. J. Am. Chem. Soc. 2019, 141, 952-960. [CrossRef]

35. Fujitsuka, M.; Cho, D.W.; Iwamoto, T.; Yamago, S.; Majima, T. Size-dependent fluorescence properties of [n] cycloparaphenylenes $(\mathrm{n}=8-13)$, hoop-shaped $\pi$-conjugated molecules. Phys. Chem. Chem. Phys. 2012, 14, 14585-14588. [CrossRef]

36. Nishihara, T.; Segawa, Y.; Itami, K.; Kanemitsu, Y. Excited states in cycloparaphenylenes: Dependence of optical properties on ring length. J. Phys. Chem. Lett. 2012, 3, 3125-3128. [CrossRef]

37. Camacho, C.; Niehaus, T.A.; Itami, K.; Irle, S. Origin of the size-dependent fluorescence blueshift in [n] cycloparaphenylenes. Chem. Sci. 2013, 4, 187-195. [CrossRef]

38. Qiu, L.; Peña-Alvarez, M.; Taravillo, M.; Evans, P.J.; Darzi, E.R.; Jasti, R.; Mayorga Burrezo, P.; López Navarrete, J.T.; Baonza, V.G.; Casado, J.; et al. High-Pressure Chemistry and the Mechanochemical Polymerization of [5]-Cyclo-p-phenylene. Chem. Eur. J. 2017, 23, 16593-16604. [CrossRef]

39. Qiu, L.; Peña-Alvarez, M.; Taravillo, M.; Baonza, V.G.; Casado, J.; Kertesz, M. Mechanochemistry in [6] Cycloparaphenylene: A Combined Raman Spectroscopy and Density Functional Theory Study. Chem. Phys. Chem. 2018, 19, 1903-1916. [CrossRef]

40. Peña-Alvarez, M.; Qiu, L.; Baonza, V.G.; Taravillo, M.; Kertesz, M. Casado, Molecules under Pressure: The Case of [n] Cycloparaphenylenes. J. Chem. Mat. 2019, 31, 6443-6452. [CrossRef]

41. Jezowski, S.R.; Zhu, L.; Wang, Y.; Rice, A.P.; Scott, G.W.; Bardeen, C.J.; Chronister, E.L. Pressure catalyzed bond dissociation in an anthracene cyclophane photodimer. J. Am. Chem. Soc. 2012, 134, 7459-7466. [CrossRef]

42. Bini, R.; Ceppatelli, M.; Citroni, M.; Schettino, V. Pressure catalyzed bond dissociation in an anthracene cyclophane photodimer. Chem. Phys. 2012, 398, 262-268. [CrossRef]

43. Ciabini, L.; Gorelli, F.A.; Santoro, M.; Bini, R.; Schettino, V.; Mezouar, M. High-pressure and high-temperature equation of state and phase diagram of solid benzene. Phys. Rev. B 2005, 72, 094108. [CrossRef]

44. Thiéry, M.M.; Léger, J.M. High pressure solid phases of benzene. I. Raman and X-ray studies of C6H6 at 294 $\mathrm{K}$ up to $25 \mathrm{GPa}$. J. Chem. Phys. 1988, 89, 4255-4271. [CrossRef]

45. Baker, K.N.; Fratini, A.V.; Resch, T.; Knachel, H.C.; Adams, W.W.; Socci, E.P.; Farmer, B.L. Crystal structures, phase transitions and energy calculations of poly (p-phenylene) oligomers. Polymer 1993, 34, 1571-1587. [CrossRef]

46. Fukushima, T.; Sakamoto, H.; Tanaka, K.; Hijikata, Y.; Irle, S.; Itami, K. Polymorphism of [6] Cycloparaphenylene for Packing Structure-dependent Host-Guest Interaction. Chem. Lett. 2017, 46, 855-857. [CrossRef]

47. Ciabini, L.; Santoro, M.; Gorelli, F.A.; Bini, R.; Schettino, V.; Raugei, S. Triggering dynamics of the high-pressure benzene amorphization. Nat. Mater. 2007, 6, 39. [CrossRef]

48. Ciabini, L.; Santoro, M.; Bini, R.; Schettino, V. High pressure reactivity of solid benzene probed by infrared spectroscopy. J. Chem. Phys. 2002, 116, 2928-2935. [CrossRef]

49. Mao, H.K.; Bell, P.M.; Hemley, R. Ultrahigh pressures: Optical observations and Raman measurements of hydrogen and deuterium to 1.47 Mbar. J. Phys. Rev. Lett. 1985, 55, 99. [CrossRef]

50. Martin, C.M.; Cai, Q.; Guha, S.; Graupner, W.; Chandrasekhar, M.; Handrasekhar, H.R. Raman modes in oligophenyls under hydrostatic pressure. Phys. Stat. Sol. 2004, 241, 3339-3344. [CrossRef]

51. Segawa, Y.; Miyamoto, S.; Omachi, H.; Matsuura, S.; Senel, P.; Sasamori, T.; Tokitoh, N.; Itami, K. Concise synthesis and crystal structure of [12] cycloparaphenylene. Angew. Chem. Int. Ed. 2011, 50, 3244-3248. [CrossRef]

52. Xia, J.; Jasti, R. Synthesis, characterization, and crystal structure of [6] cycloparaphenylene. Angew. Chem. Int. Ed. 2012, 51, 2474-2476. [CrossRef]

53. Momicchioli, F.; Bruni, M.C.; Baraldi, I. Fluorescence and absorption spectra of polyphenyls. Theoretical study on the band shape. J. Phys. Chem. 1972, 76, 3983-3990. [CrossRef]

54. Martin, R.E.; Diederich, F. Linear Monodisperse $\pi$-Conjugated Oligomers: Model Compounds for Polymers and More. Angew. Chem. Int. Ed. 1999, 38, 1350-1377. [CrossRef]

55. Mabbs, R.; Nijegorodov, N.; Downey, W.S. Fluorescence and laser properties of D2-, C2-and D3 symmetry series oligophenylenes. Spectrochim. Acta Part A 2003, 59, 1329-1339. [CrossRef] 
56. Adamska, L.; Nayyar, I.; Chen, H.; Swan, A.K.; Oldani, N.; Fernandez-Alberti, S.; Golder, M.R.; Jasti, R.; Doorn, S.K.; Tretiak, S. Self-trapping of excitons, violation of Condon approximation, and efficient fluorescence in conjugated cycloparaphenylenes. Nano Lett. 2014, 14, 6539-6546. [CrossRef]

57. Darzi, E.R.; Sisto, T.J.; Jasti, R. Selective syntheses of [7]-[12] cycloparaphenylenes using orthogonal Suzuki-Miyaura cross-coupling reactions. J. Org. Chem. 2012, 77, 6624-6628. [CrossRef]

58. Wong, B.M. Optoelectronic properties of carbon nanorings: Excitonic effects from time-dependent density functional theory. J. Phys. Chem. C 2009, 113, 21921-21927. [CrossRef]

59. Fanetti, S.; Citroni, M.; Malavasi, L.; Artioli, G.A.; Postorino, P.; Bini, R. High-pressure optical properties and chemical stability of picene. J. Phys. Chem. C 2013, 117, 5343-5351. [CrossRef]

60. Guha, S.; Graupner, W.; Yang, S.; Chrandrasekhar, M.; Chrandrasekhar, H.R.; Leising, G. Optical Properties of Poly (Para-Phenylenes) under High Pressure. Phys. Stat. Sol. 2004, 211, 177-188. [CrossRef]

61. Citroni, M.; Bini, R.; Foggi, P.; Schettino, V. Role of excited electronic states in the high-pressure amorphization of benzene. Proc. Natl. Acad. Sci. USA 2008, 105, 7658-7663. [CrossRef]

62. Drickamer, H.G.; Frank, C.W. Electronic Transitions and the High Pressure Chemistry and Physics of Solids; Springer: Berlin/Heidelberg, Germany, 1973.

63. Fujitsuka, M.; Lu, C.; Iwamoto, T.; Kayahara, E.; Yamago, S.; Majima, T. Properties of triplet-excited [ $n$ ] cycloparaphenylenes $(n=8-12)$ : Excitation energies lower than those of linear oligomers and polymers. J. Phys. Chem. A 2014, 118, 4527-4532. [CrossRef]

64. Colthrup, N.B.; Daly, L.H.; Wiberley, S.E. Introduction to Infrared and Raman Spectroscopy, 3rd ed.; Academic Press: San Diego, CA, USA, 1990.

65. Alvarez, M.P.; Delgado, M.C.R.; Taravillo, M.; Baonza, V.G.; Navarrete, J.T.L.; Evans, P.; Jasti, R.; Yamago, S.; Kertesz, M.; Casado, J. The Raman fingerprint of cyclic conjugation: The case of the stabilization of cations and dications in cycloparaphenylenes. J. Chem. Sci. 2016, 7, 3494-3499. [CrossRef]

66. Froyer, G.; Goblot, J.Y.; Guilbert, J.L.; Maurice, F.; Pelous, Y. Poly(para phenylene): Some properties related to the synthesis method. J. Phys. Colloq. 1983, 44, C3-745-C3-748.

67. Mao, H.K.; Bell, P.M.; Shaner, J.W.; Steinberg, D.J. Specific volume measurements of Cu, Mo, Pd, and Ag and calibration of the ruby R 1 fluorescence pressure gauge from 0.06 to 1 Mbar. J. App. Phys. 1978, 49, 3279-3283. [CrossRef]

68. Agilent Technologies Ltd. CrysAlis PRO; Agilent Technologies Ltd.: Santa Clara, CA, USA, 2014.

69. Evans, P.R.; Murshudov, G.N. How good are my data and what is the resolution? Acta Crystallogr. Sect. D Biol. Crystallogr. 2013, 69, 1204-1214. [CrossRef]

70. Winn, M.D.; Ballard, C.C.; Cowtan, K.D.; Dodson, E.J.; Emsley, P.; Evans, P.R.; Keegan, R.M.; Krissinel, E.B.; Leslie, A.G.; McCoy, A.; et al. Overview of the CCP4 suite and current developments. J. Acta Crystallogr. Sect. D Biol. Crystallogr. 2011, 67, 235-242. [CrossRef]

71. Winter, G. xia2: An expert system for macromolecular crystallography data reduction. J. Appl. Cryst. 2010, 43, 186-190. [CrossRef]

72. Winter, G.; Waterman, D.G.; Parkhurst, J.M.; Brewster, A.S.; Gildea, R.J.; Gerstel, M.; Fuentes-Montero, L.; Vollmar, M.; Michels-Clark, T.; Young, I.D.; et al. DIALS: Implementation and evaluation of a new integration package. Acta Crystallogr. Sect. D Biol. Crystallogr. 2018, 74, 85-97. [CrossRef]

73. Evans, P. Scaling and assessment of data quality. Acta Crystallogr. Sect. D Biol. Crystallogr. 2006, 62, 72-82. [CrossRef]

74. Sheldrick, G.M. SHELXT-Integrated space-group and crystal-structure determination. Acta Crystallogr. Sect. A Found. Crystallogr. 2015, 71, 3-8. [CrossRef]

75. Dolomanov, O.V.; Bourhis, L.J.; Gildea, R.J.; Howard, J.A.K.; Puschmann, H. OLEX2: A complete structure solution, refinement and analysis program. J. Appl. Cryst. 2009, 42, 339-341. [CrossRef]

76. Macrae, C.F.; Edgington, P.R.; McCabe, P.; Pidcock, E.; Shields, G.P.; Taylor, R.; Towler, M.; Streek, J.V.D. Mercury CSD 2.0-New features for the visualization and investigation of crystal structures. J. Appl. Cryst. 2006, 39, 453-457. [CrossRef]

77. Mackenzie, C.F.; Spackman, P.R.; Jayatilaka, D.; Spackman, M.A. CrystalExplorer model energies and energy frameworks: Extension to metal coordination compounds, organic salts, solvates and open-shell systems. IUCrJ 2017, 4, 575-587. [CrossRef] [PubMed] 
78. Bini, R.; Ballerini, R.; Pratesi, G.; Jodl, H.J. Experimental setup for Fourier transform infrared spectroscopy studies in condensed matter at high pressure and low temperatures. Rev. Sci. Instrum. 1997, 68, 3154-3160. [CrossRef]

79. Peña-Alvarez, M.; Qiu, L.; Taravillo, M.; Baonza, V.G.; Ruiz Delgado, M.C.; Yamago, S.; Jasti, R.; López Navarrete, J.T.; Casado, J.; Kertesz, M. From linear to cyclic oligoparaphenylenes: Electronic and molecular changes traced in the vibrational Raman spectra and reformulation of the bond length alternation pattern. Phys. Chem. Chem. Phys. 2016, 18, 11683-11692. [CrossRef] [PubMed]

80. Baonza, V.G.; Taravillo, M.; Arencibia, A.; Cáceres, M.; Núñez, J. Diamond as pressure sensor in high-pressure Raman spectroscopy using sapphire and other gem anvil cells. J. Raman Spectrosc. 2003, 34, 264-270. [CrossRef]

Sample Availability: Samples of the compounds are not available from the authors.

(C) 2019 by the authors. Licensee MDPI, Basel, Switzerland. This article is an open access article distributed under the terms and conditions of the Creative Commons Attribution (CC BY) license (http://creativecommons.org/licenses/by/4.0/). 